\title{
Analytical approach for determining the mean water level profile in an estuary with substantial fresh water discharge
}

\author{
Huayang Cai ${ }^{1,2}$, Hubert H. G. Savenije ${ }^{3}$, Chenjuan Jiang ${ }^{4}$, Lili Zhao ${ }^{5}$, and Qingshu Yang ${ }^{1,2}$ \\ ${ }^{1}$ Institute of Estuarine and Coastal Research, School of Marine Sciences, Sun Yat-sen University, Guangzhou 510275, China \\ ${ }^{2}$ State and Local Joint Engineering Laboratory of Estuarine Hydraulic Technology, Guangzhou 510275, China \\ ${ }^{3}$ Water Resources Section, Delft University of Technology, Delft, the Netherlands \\ ${ }^{4}$ School of Hydraulic, Energy and Power Engineering, Yangzhou University, Yangzhou 225127, China \\ ${ }^{5}$ State Key Laboratory of Hydrology and Hydraulic Engineering, Hohai University, Nanjing 210098, China \\ Correspondence to: Qingshu Yang (yangqsh@mail.sysu.edu.cn)
}

Received: 7 August 2015 - Published in Hydrol. Earth Syst. Sci. Discuss.: 26 August 2015

Revised: 18 January 2016 - Accepted: 11 March 2016 - Published: 18 March 2016

\begin{abstract}
The mean water level in estuaries rises in the landward direction due to a combination of the density gradient, the tidal asymmetry, and the backwater effect. This phenomenon is more prominent under an increase of the fresh water discharge, which strongly intensifies both the tidal asymmetry and the backwater effect. However, the interactions between tide and river flow and their individual contributions to the rise of the mean water level along the estuary are not yet completely understood. In this study, we adopt an analytical approach to describe the tidal wave propagation under the influence of substantial fresh water discharge, where the analytical solutions are obtained by solving a set of four implicit equations for the tidal damping, the velocity amplitude, the wave celerity, and the phase lag. The analytical model is used to quantify the contributions made by tide, river, and tide-river interaction to the water level slope along the estuary, which sheds new light on the generation of backwater due to tide-river interaction. Subsequently, the method is applied to the Yangtze estuary under a wide range of river discharge conditions where the influence of both tidal amplitude and fresh water discharge on the longitudinal variation of the mean tidal water level is explored. Analytical model results show that in the tide-dominated region the mean water level is mainly controlled by the tide-river interaction, while it is primarily determined by the river flow in the river-dominated region, which is in agreement with previous studies. Interestingly, we demonstrate that the effect of the tide alone is most important in the transitional zone, where the ratio of velocity amplitude to river flow velocity
\end{abstract}

approaches unity. This has to do with the fact that the contribution of tidal flow, river flow, and tide-river interaction to the residual water level slope are all proportional to the square of the velocity scale. Finally, we show that, in combination with extreme-value theory (e.g. generalized extremevalue theory), the method may be used to obtain a first-order estimation of the frequency of extreme water levels relevant for water management and flood control. By presenting these analytical relations, we provide direct insight into the interaction between tide and river flow, which will be useful for the study of other estuaries that experience substantial river discharge in a tidal region.

\section{Introduction}

It is of both theoretical and practical importance to understand the dynamics of wave propagation under the backwater effect, for instance when a river is backed up by an obstruction, such as a weir or a bridge, by a confluence with a larger river, or by an ocean tide, resulting in a rise of the water level upstream of the obstruction. Generally, the backwater effect can be quantified by using the variation of the water level slope in the momentum equation. Many researchers have explored the backwater effect in open channels by disregarding one or more terms in the momentum equation (detailed review can be found in Dottori et al., 2009). Among them, the most well-known is Jones' formula (Jones, 1916), which is an analytical expression of the water level slope as a function 
of fresh water discharge and geometric characteristics (e.g. bottom slope, cross-sectional area, hydraulic radius, Manning's coefficient). However, the backwater effect induced by an ocean tide in interaction with a river flood in an estuary still remains subject for further investigation.

It has been suggested that the mean water surface of a tidal river is driven by the fortnightly fluctuation due to the spring-neap changes in tidal amplitude at the seaward side, but it also features a consistent increase in the landward direction, caused by the tide-river interaction (e.g. LeBlond, 1979; Godin and Martinez, 1994; Buschman et al., 2009; Sassi and Hoitink, 2013) and the density gradient (e.g. Savenije, 2005, 2012). The key to understand the interplay between tide and fresh water discharge in an estuary lies in the friction term of the momentum equation, which is usually decomposed into different components contributed by tide, river, and tide-river interaction (Dronkers, 1964; Godin, 1991, 1999; Buschman et al., 2009; Sassi and Hoitink, 2013). In particular, Dronkers (1964) used the Chebyshev polynomials approach to approximate the quadratic velocity in the friction term, in which the resulted approximation consists of four terms with coefficients depending on the ratio between river flow velocity and tidal velocity amplitude. Godin $(1991,1999)$ proposed a simpler approximation that retains only the first- and third-order terms as a function of the non-dimensionalized velocity, which is comparable with Dronkers' formula in terms of accuracy.

It was shown by Godin (1999) that the sub-tidal water level can be reconstructed by a simple linear regression equation as a function of fresh water discharge and tidal range, suggesting a strong correlation between sub-tidal water level and tide-river interaction. To understand the basic mechanisms of the tide-river interaction in the Columbia River, Jay and Flinchem (1997) and Kukulka and Jay (2003a, b) employed a wavelet tidal analysis method to decompose the time series of water levels into different components (diurnal, semidiurnal, quarter-diurnal, and mean flow), which allows for taking account of the tidal asymmetry (i.e. interaction between different tidal constituents). They also derived a linear regression model for describing the sub-tidal water level as a function of fresh water discharge, tidal range, and atmospheric pressure. Similar linear regression models were proposed by Buschman et al. (2009), Sassi and Hoitink (2013) and Guo et al. (2015) for predicting the sub-tidal water level on the basis of the decomposed sub-tidal friction in the momentum equation. In addition, Jay et al. (2015) demonstrated that power spectra, continuous wavelet transforms, and harmonic analyses are useful instruments to understand external changes (e.g. tide, river flow, upwelling, and downwelling) on the variations of along-channel water level. Previous studies did qualitatively assess the relative importance of tidal flow (or tidal asymmetry), river flow, and tide-river interaction on the residual water level by decomposing the tidally averaged friction term, which is balanced by the water level surface gradient (or residual water level slope). These stud- ies showed that the river-tide interaction contributes significantly to the tidally averaged friction in the tide-dominated region, while in the river-dominated region the tidally averaged friction is mainly controlled by the river flow. The contribution made by tidal asymmetry to the tidally averaged friction appeared relatively small (e.g. Buschman et al., 2009; Sassi and Hoitink, 2013). However, the underlying mechanism of the rising residual water level along the estuary is not yet fully understood. In particular, we note that the residual water level itself (which is implicitly included in the denominator of the friction term in the momentum equation) may substantially influence the tidally averaged friction, especially in the high river flow conditions with large residual water level (e.g. in the Yangtze estuary). Thus, it is difficult to analytically quantify the contributions of tidal flow, river flow, and tide-river interaction on the tidally averaged friction (and hence residual water level slope) since it requires the unknown parameter of residual water level. In addition, we note that the decomposition of the tidally averaged friction term requires long-term measurements of velocity, which are not always available in reality. In this paper, we adopt an analytical model for tidal hydrodynamics (Cai et al., 2014b) to further study the tide-river dynamics and its impact on the residual water level in estuaries with substantial fresh water discharge. We limit the analysis to the interaction between the predominant tidal constituent (e.g. $\mathrm{M}_{2}$ ) and the river flow, aiming to derive fully explicit analytical expressions describing the basic mechanisms that cause the rise of mean water level along the estuary. The proposed method is simple and only requires a minimum amount of data. More importantly, the analytical method provides direct insight into the dominant processes that determine river-tide interaction. As a result, it allows us to better understand how tidal propagation in estuaries is affected by fresh water discharge.

The current work is not just an application of a model to a case study, but an analysis that provides new analytical tools to assess the influence of fresh water discharge on water levels in estuaries. For the first time, we used a fully analytical approach to quantify the contributions made by different components (tide, river, and tide-river interaction) to the residual water level, which sheds new light on how backwaters are generated as a result of tide-river interaction. The method is subsequently used to estimate the frequency of extreme high water along the estuary, which is particularly useful for water management and flood control.

In the following section, the general methodology for describing the tidal wave propagation under riverine influence and contributions made by different frictional components (river, tide, tide-river interaction) to the rise of mean water level are presented. This is followed by an application to the Yangtze estuary where there is a notable influence of fresh water discharge on tidal dynamics (Sect. 3). We explored the response of the mean water level as a function of tidal forcing imposed at the mouth and the fresh water discharge from 
upstream. Subsequently, the method has been used to predict the envelopes of high water and low water in the Yangtze estuary. In particular, it is shown that the analytical model can be used to estimate the likelihood of extreme high water levels along the estuary for given probability of exceedance. Finally, conclusions are summarized in Sect. 4.

\section{Methodology}

\subsection{Shape of an estuary}

For the derivation of analytical solutions of the tidal hydrodynamics equations in estuaries, we require geometric functions to describe the estuary geometry, such as constant geometry (e.g. Ippen, 1966), a linear function (e.g. Gay and O'Donnell, 2007, 2009), a power function (e.g. Prandle and Rahman, 1980), or an exponential function (e.g. Savenije, $1998,2001,2005,2012)$. Among these, the most common approach is to use an exponential function to describe the cross-sectional area, width, and depth in a tidally averaged scale. This method works very well in a tide-dominated estuary, which usually has a typical funnel shape. However, as opposed to what is generally done, the cross-sectional area and stream width do not converge to zero, but to constant river-dominated values. To better represent the geometry of such funnel-prismatic estuaries, we propose the following expressions to describe the longitudinal variation of crosssectional area $\bar{A}$ and stream width $\bar{B}$ (see also Toffolon et al., 2006; Cai et al., 2014b):

$\bar{A}=\overline{A_{\mathrm{r}}}+\left(\overline{A_{0}}-\overline{A_{\mathrm{r}}}\right) \exp \left(-\frac{x}{a}\right)$,

$\bar{B}=\overline{B_{\mathrm{r}}}+\left(\overline{B_{0}}-\overline{B_{\mathrm{r}}}\right) \exp \left(-\frac{x}{b}\right)$,

where $x$ is the distance (starting from the estuary mouth), $\overline{A_{0}}$ and $\overline{B_{0}}$ represent the cross-sectional area and stream width evaluated at the estuary mouth, $\overline{A_{\mathrm{r}}}$ and $\overline{B_{\mathrm{r}}}$ represent the asymptotic riverine cross-sectional area and stream width (the overbar denotes the tidally averaged value), while $a$ and $b$ represent the convergence lengths of the cross-sectional area and stream width, respectively. This equation accounts for not only the exponential shape in the seaward part of the estuary, but also the nearly prismatic channel in the landward part. Assuming a near rectangular cross section, the tidally averaged depth is given by $\bar{h}=\bar{A} / \bar{B}$.

Figure 1 illustrates the variation of the estuarine shape for different convergence lengths. In this approach, there is no need for an inflection point to cater for the transition from a funnel shape to a prismatic channel.

\subsection{Analytical model for tidal hydrodynamics}

In a tidal river, we usually observe that the tidally averaged water level rises in landward direction (e.g. Godin and Martinez, 1994). This residual water level increases with the

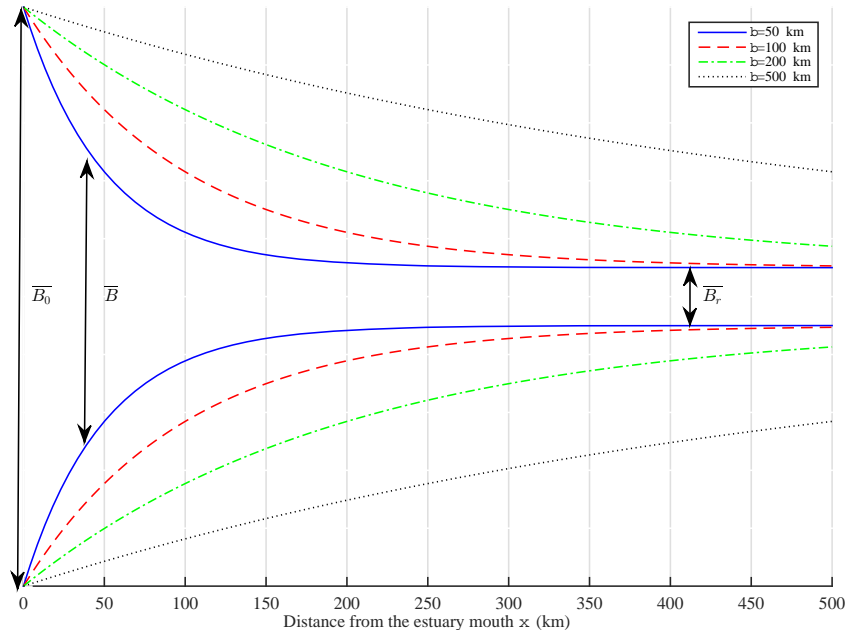

Figure 1. Variation of the estuarine shape (Eq. 2) under different width convergence length $b$ for given values of $\overline{B_{0}}=10 \mathrm{~km}$ and $\overline{B_{\mathrm{r}}}=1 \mathrm{~km}$.

fresh water discharge. In order to explore the underlying mechanism of this phenomenon and quantify the contributions of tide, river, and tide-river interaction to the increased residual water level, an analytical solution are invaluable tool since it provides direct insight into the tidal wave propagation under the influence of river discharge.

The density-induced pressure in the momentum equation is upstream directed and counteracted by a residual water level that equals $1.25 \%$ of the mean water depth over the length of salt intrusion, having a significant influence on salt intrusion through gravitational circulation (Savenije, 2005, 2012). In the Yangtze estuary the water level rise due to the density gradient is around $0.12 \mathrm{~m}$ (corresponding to an estuary depth of $9.5 \mathrm{~m}$ ) over the salt intrusion length (approximately $50 \mathrm{~km}$ ). Thus the density-induced slope is rather small (around $3.0 \times 10^{-8}$ ) compared to the frictional dissipation induced by river discharge. Consequently, we neglect the effect of the density gradient on the mean water level profile in this paper.

It has been suggested by Cai et al. (2014a, b) that the hydrodynamics in a tidal river is mainly determined by the four dimensionless parameters (see Table 1), including the tidal amplitude to depth ratio $\zeta$ (representing the boundary condition in the seaward side), the estuary shape number $\gamma$ (indicating the channel convergence), the friction number $\chi$ (representing the frictional dissipation), and the dimensionless river discharge $\varphi$ (representing the effect of fresh water discharge). Note that in Table $1 \eta$ indicates the tidal amplitude, $v$ is the velocity amplitude, $U_{\mathrm{r}}$ is the river flow velocity, $\omega$ is the tidal frequency, $g$ is the gravity acceleration, $K$ is the Manning-Strickler friction coefficient, $r_{\mathrm{S}}$ is the storage width ratio, and $c_{0}$ is the classical wave celerity defined as $c_{0}=\sqrt{g \bar{h} / r_{\mathrm{S}}}$. It is important to recognize that we use a new 
definition for the estuary shape number as suggested by Cai et al. (2014b) to account for the asymptotic adjustment to the river cross section, the difference being a factor $\left(1-\overline{A_{\mathrm{r}}} / \bar{A}\right)$, which varies with distance although it remains close to unity in the most downstream reach of the estuary.

We use the analytical model for tidal dynamics proposed by Cai et al. (2014a, b), in which the solutions of the main tidal dynamics are obtained by means of solving a set of four implicit equations for the main dynamics, including tidal damping or amplification, wave celerity (or speed), velocity amplitude, and phase lag. The main dependent parameters are described by the following four variables (see Table 1): $\delta$ represents the amplification number describing the damping $(\delta<0)$ or amplified $(\delta>0)$ rate of along-channel tidal amplitude, $\mu$ the velocity number indicating the ratio of actual velocity amplitude to that in a frictionless prismatic channel, $\lambda$ the celerity number representing the classical wave celerity $c_{0}$ scaled by the actual wave celerity (speed) $c$, and $\varepsilon$ representing the phase lag between high water (HW) and high water slack (HWS) or between low water (LW) and low water slack (LWS). It is noted that $0 \leq \varepsilon \leq \pi / 2$, where $\varepsilon=0$ indicates the tidal wave characterized by a standing wave, while $\varepsilon=\pi / 2$ suggests a progressive wave. For a predominant tide (e.g. $\left.\mathrm{M}_{2}\right)$, the phase lag is determined by $\varepsilon=\pi-\left(\phi_{Z}-\phi_{U}\right)$, in which $\phi_{Z}$ and $\phi_{U}$ represent the phase of water level and velocity, respectively (Savenije et al., 2008).

The key aspect of this method is to derive an analytical expression for tidal amplification or damping using the socalled "envelope method", i.e. by subtracting the envelope curves at HW and LW (for details see Cai et al., 2014b). In a Lagrangean reference frame, we assume that the velocity of a moving water particle $V$ consists of a steady component $U_{\mathrm{r}}$, generated by the fresh water discharge, and a time-dependent constituent $U_{t}$, introduced by the tidal flow:

$V=U_{t}-U_{\mathrm{r}}=v \sin (\omega t)-Q / \bar{A}$

where $t$ is time and $Q$ is the fresh water discharge (treated as a constant during the tidal wave propagation). Consequently, the velocity accounting for fresh water discharge at $\mathrm{HW}$ is given by

$V_{\mathrm{HW}}=v \sin (\varepsilon)-U_{r}=v[\sin (\varepsilon)-\varphi]$,

and similarly for LW:

$V_{\mathrm{LW}}=-v \sin (\varepsilon)-U_{r}=-v[\sin (\varepsilon)+\varphi]$.

Making use of Eqs. (4) and (5) and using the envelope method, the resulted damping equation, describing the tidal amplification or damping as a result of the balance between convergence $(\gamma \theta)$ and friction $(\chi \mu \lambda \Gamma)$, is given by

$\delta=\frac{\mu^{2}(\gamma \theta-\chi \mu \lambda \Gamma)}{1+\mu^{2} \beta}$, where $\theta, \beta$, and $\Gamma$ account for the effect of river discharge. The expressions of $\theta$ and $\beta$ are shown in Table 1, while

$\Gamma=\frac{1}{\pi}\left[p_{1}-2 p_{2} \varphi+p_{3} \varphi^{2}\left(3+\mu^{2} \lambda^{2} / \varphi^{2}\right)\right]$

is a friction factor obtained by using Chebyshev polynomials (Dronkers, 1964) to represent the non-linear friction term in the momentum equation

$F=\frac{V|V|}{K^{2} \bar{h}^{4 / 3}} \approx \frac{1}{K^{2} \bar{h}^{4 / 3} \pi}\left(p_{0} v^{2}+p_{1} v V+p_{2} V^{2}+p_{3} V^{3} / v\right)$,

where $p_{i}(i=0,1,2,3)$ represent the Chebyschev coefficients (see Dronkers, 1964, p. 301), which are functions of $\varphi$ through $\alpha=\arccos (-\varphi)$ :

$$
\begin{aligned}
& p_{0}=-\frac{7}{120} \sin (2 \alpha)+\frac{1}{24} \sin (6 \alpha)-\frac{1}{60} \sin (8 \alpha), \\
& p_{1}=\frac{7}{6} \sin (\alpha)-\frac{7}{30} \sin (3 \alpha)-\frac{7}{30} \sin (5 \alpha)+\frac{1}{10} \sin (7 \alpha), \\
& p_{2}=\pi-2 \alpha+\frac{1}{3} \sin (2 \alpha)+\frac{19}{30} \sin (4 \alpha)-\frac{1}{5} \sin (6 \alpha), \\
& p_{3}=\frac{4}{3} \sin (\alpha)-\frac{2}{3} \sin (3 \alpha)+\frac{2}{15} \sin (5 \alpha) .
\end{aligned}
$$

The coefficients $p_{1}, p_{2}$, and $p_{3}$ quantify the contributions made by linear, quadratic, and cubic frictional interaction, respectively. In Fig. 2, it appears that the value of $p_{0}$ is small with respect to the values of the other coefficients. We observe that the values of $p_{1}$ and $p_{2}$ increase with increasing $\varphi$ until a maximum value is reached, after which $p_{1}$ converges to 0 while $p_{2}$ converges to $-\pi$. The value of $p_{3}$ is decreased with $\varphi$ and it reduces to 0 for $\varphi<1$. For $\varphi \geq 1$, $p_{0}=p_{1}=p_{3}=0$ and $p_{2}=-\pi$, so that Eq. (8) reduces to $F=V^{2} /\left(K^{2} \bar{h}^{4 / 3}\right)$. If $\varphi=0$ (or $\left.Q=0\right), p_{0}=p_{2}=0, p_{1}=$ $16 / 15$, and $p_{3}=32 / 15$, so that Eq. (8) reduces to

$$
F=\frac{16}{15 \pi} \frac{v^{2}}{K^{2} \bar{h}^{4 / 3}}\left[\frac{V}{v}+2\left(\frac{V}{v}\right)^{3}\right] .
$$

It is worth noting that the derived tidal damping Eq. (6) does account for the tidal asymmetry induced by the interaction between tide and river flow, since we described the velocity of a moving particle at $\mathrm{HW}$ and LW as a harmonic wave in combination with a river flow velocity, i.e. Eqs. (4) and (5).

Apart from the damping Eq. (6), the other three dimensionless equations are summarized as follows (Cai et al., 2014b).

The scaling equation describes how the ratio of velocity amplitude to tidal amplitude depends on phase lag and wave speed (wave celerity):

$\mu=\frac{\sin (\varepsilon)}{\lambda}=\frac{\cos (\varepsilon)}{\gamma-\delta}$, 
Table 1. Definitions of parameters used in the governing Eqs. (6), (14), (15), and (16).

\begin{tabular}{ll}
\hline Local variables & Dependent variables \\
\hline Dimensionless tidal amplitude & Amplification number \\
$\zeta=\eta / \bar{h}$ & $\delta=c_{0} \mathrm{~d} \eta /(\eta \omega \mathrm{d} x)$ \\
\hline Estuary shape number & Velocity number \\
$\gamma=c_{0}\left(\bar{A}-\overline{A_{\mathrm{r}}}\right) /(\omega a \bar{A})$ & $\mu=v /\left(r_{\mathrm{S}} \zeta c_{0}\right)=v \bar{h} /\left(r_{\mathrm{S}} \eta c_{0}\right)$ \\
\hline Friction number & Celerity number \\
$\chi=r_{\mathrm{S}} g c_{0} \zeta\left[1-(4 \zeta / 3)^{2}\right]^{-1} /\left(\omega K^{2} \bar{h}\right)$ & $\lambda=c_{0} / c$ \\
\hline Dimensionless river discharge & Phase lag \\
$\varphi=U_{\mathrm{r}} / v$ & $\varepsilon=\pi / 2-\left(\phi_{\mathrm{Z}}-\phi_{U}\right)$ \\
\hline \multicolumn{2}{c}{$\beta=\theta-r_{\mathrm{S}} \zeta \varphi /(\mu \lambda), \theta=1-(\sqrt{1+\zeta}-1) \varphi /(\mu \lambda)$} \\
\hline
\end{tabular}

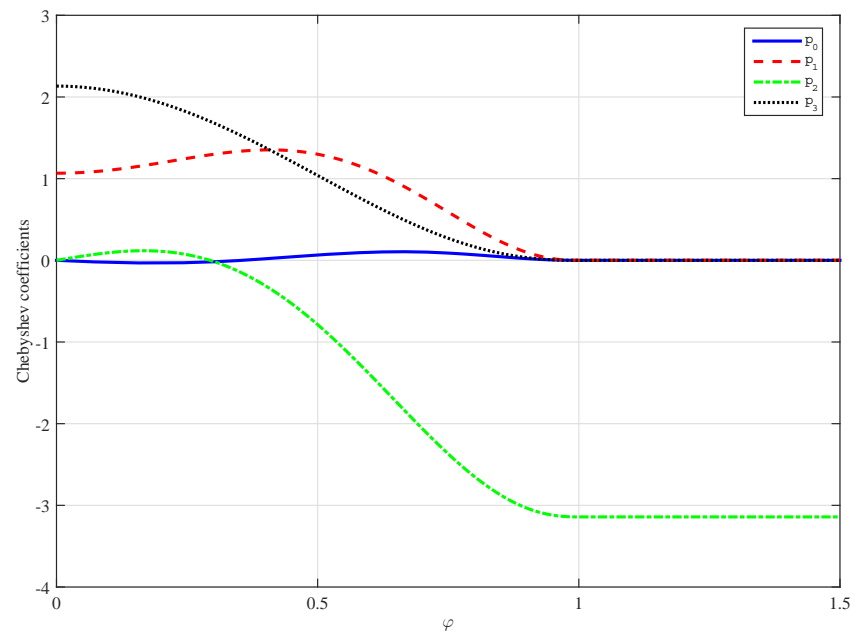

Figure 2. Variation of the Chebyshev coefficients $p_{i}(i=0,1,2,3)$ as a function of the dimensionless river discharge number $\varphi$.

The wave celerity (or speed) equation describes how the wave speed depends on the balance between convergence and tidal damping/amplification:

$\lambda^{2}=1-\delta(\gamma-\delta)$,

The phase lag equation describes how the phase lag between HW and HWS depends on wave speed, convergence, and damping:

$\tan (\varepsilon)=\frac{\lambda}{\gamma-\delta}$

In Fig. 3, we see the contour plot displaying the main dependent parameters computed by solving the set of Eqs. (6), (14), (15), and (16) over a wide range of estuary shapes $(0<\gamma<4)$, and friction $(0<\chi<5)$ for given values of $\zeta=0.1, \varphi=0.5, r_{\mathrm{S}}=1$.

\subsection{Contributions of tide, river, tide-river interaction to the mean water level}

Based on the assumptions of a negligible density effect and a periodic variation of velocity, the integral of the momentum equation over a tidal period yields the mean water level gradient with respect to distance (see also Vignoli et al., 2003; Cai et al., 2014b):

$\frac{\partial \bar{z}}{\partial x}=-\bar{F}=-\overline{\frac{1}{K^{2} \bar{h}^{4 / 3} \pi}\left(p_{0} v^{2}+p_{2} v V+p_{2} V^{2}+p_{3} V^{3} / v\right)}$,

where $\bar{z}$ is the mean water level or residual water level (see Fig. 5). Substituting the total velocity $V$ from Eq. (3) into the friction term $F$ in Eq. (17) leads to three components contributing to the increase of mean water level: a tidal component

$\overline{F_{\mathrm{t}}}=\frac{1}{K^{2} \bar{h}^{4 / 3} \pi}\left(\frac{1}{2} p_{2}+p_{0}\right) v^{2}$,

a riverine component

$\overline{F_{\mathrm{r}}}=\frac{1}{K^{2} \bar{h}^{4 / 3} \pi}\left(p_{2}-p_{3} \varphi\right) U_{\mathrm{r}}^{2}$,

and tide-river interaction

$\overline{F_{\text {tr }}}=\frac{1}{K^{2} \bar{h}^{4 / 3} \pi}\left(-p_{1}-\frac{3}{2} p_{3}\right) v U_{\mathrm{r}}$.

Figure 4 shows the analytically computed gradient of the water surface over a wide range of river flow velocities $\left(U_{\mathrm{r}}=\right.$ $\left.0-2 \mathrm{~m} \mathrm{~s}^{-1}\right)$ and tidal velocity amplitudes $\left(v=0-2 \mathrm{~m} \mathrm{~s}^{-1}\right)$ for given $\bar{h}=10 \mathrm{~m}$ and $K=45 \mathrm{~m}^{1 / 3} \mathrm{~s}^{-1}$. In general, we see that both river flow velocity and velocity amplitude trigger an increase of the water surface gradient and hence the mean tidal water level.

With the thus obtained water surface gradient $\partial \bar{z} / \partial x$, the mean water surface is given by

$$
\bar{z}=\int_{0}^{x} \frac{\partial \bar{z}}{\partial x} \mathrm{~d} x=-\int_{0}^{x} \bar{F} \mathrm{~d} x=-\int_{0}^{x}\left(\overline{F_{\mathrm{t}}}+\overline{F_{\mathrm{r}}}+\overline{F_{\mathrm{tr}}}\right) \mathrm{d} x .
$$



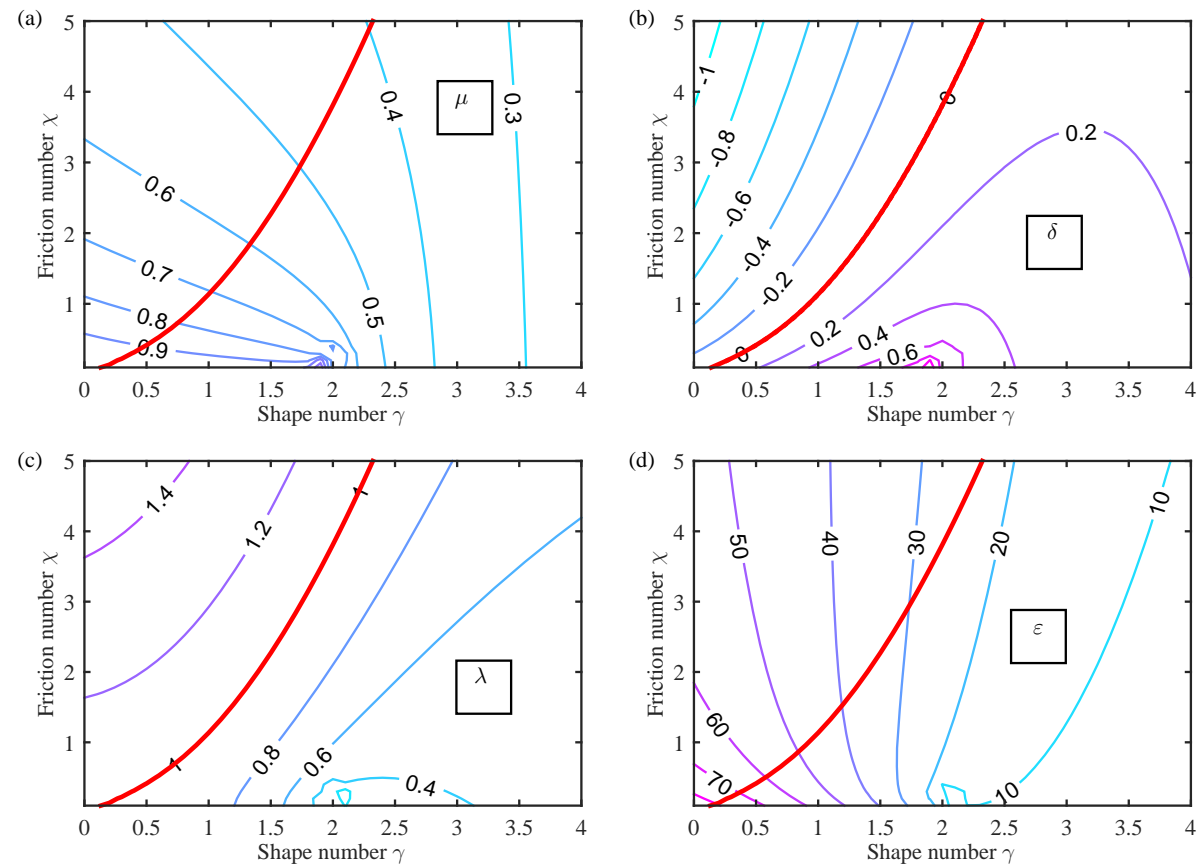

Figure 3. Analytical solutions of the four dependent dimensionless variables - (a) velocity number $\mu$, (b) amplification number $\delta$, (c) celerity number $\lambda$, and (d) phase lag $\varepsilon$ - obtained by solving the set of Eqs. (6)-(16) as a function of the estuary shape number $\gamma$ and the friction number $\chi$ for given values of $\zeta=0.1, \varphi=0.5, r_{\mathrm{S}}=1$. The thick red line represents the case for an ideal estuary $(\delta=0, \lambda=1)$.

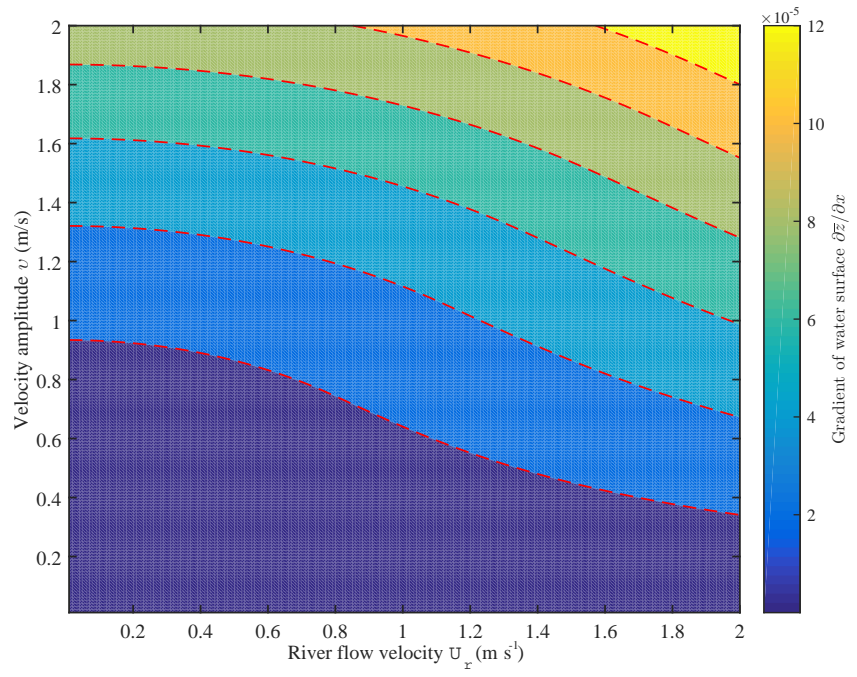

Figure 4. Contour plot of the water surface gradient $\partial \bar{z} / \partial x$ (Eq. 17) as a function of river flow velocity $U_{\mathrm{r}}$ and tidal velocity amplitude $v$ for given tidally averaged depth $\bar{h}=10 \mathrm{~m}$, Manning-Strickler friction coefficient $K=45 \mathrm{~m}^{1 / 3} \mathrm{~s}^{-1}$.

Equation (21) has been tested by comparing the analytical computations with numerical results and the good agreement suggests that it can well reproduce the correct mean water level profile along the estuary axis. For details, readers can refer to Sect. 5 of Cai et al. (2014b).

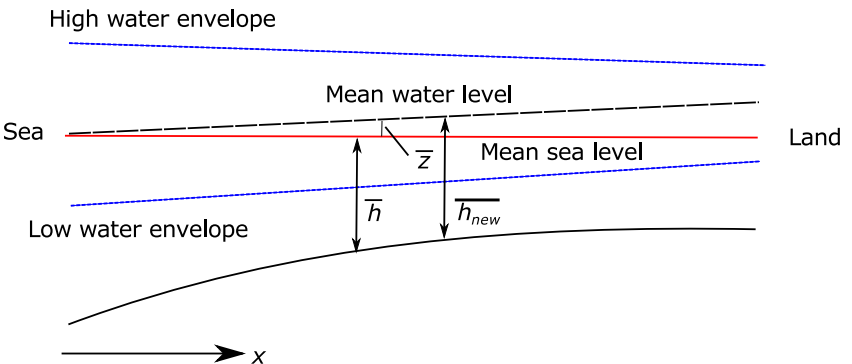

Figure 5. Sketch of the water levels in a tidal river (after Cai et al., 2014a).

An iterative procedure is involved to determine the mean water surface because the analytical expression Eq. (21) contains two unknown variables, the velocity amplitude $v$ and the updated water depth expressed as $\overline{h_{\text {new }}}=\bar{h}+\bar{z}$ (see Fig. 5).

It was shown by Godin $(1991,1999)$ that the quadratic velocity $V|V|$ in the friction term can be linearized by means of adopting the first- and third-order terms as a function of non-dimensionlized velocity scaled by the maximum possible value of the velocity (i.e. $v+U_{\mathrm{r}}$ in our case). Similar expressions as in Eqs. (18)-(20) can be obtained by using Godin's approximation to the quadratic velocity $V|V|$, which are presented in Appendix A. The Godin's approximation does perform well in the downstream part of the estuary, where the current is bi-directional. However, the approx- 


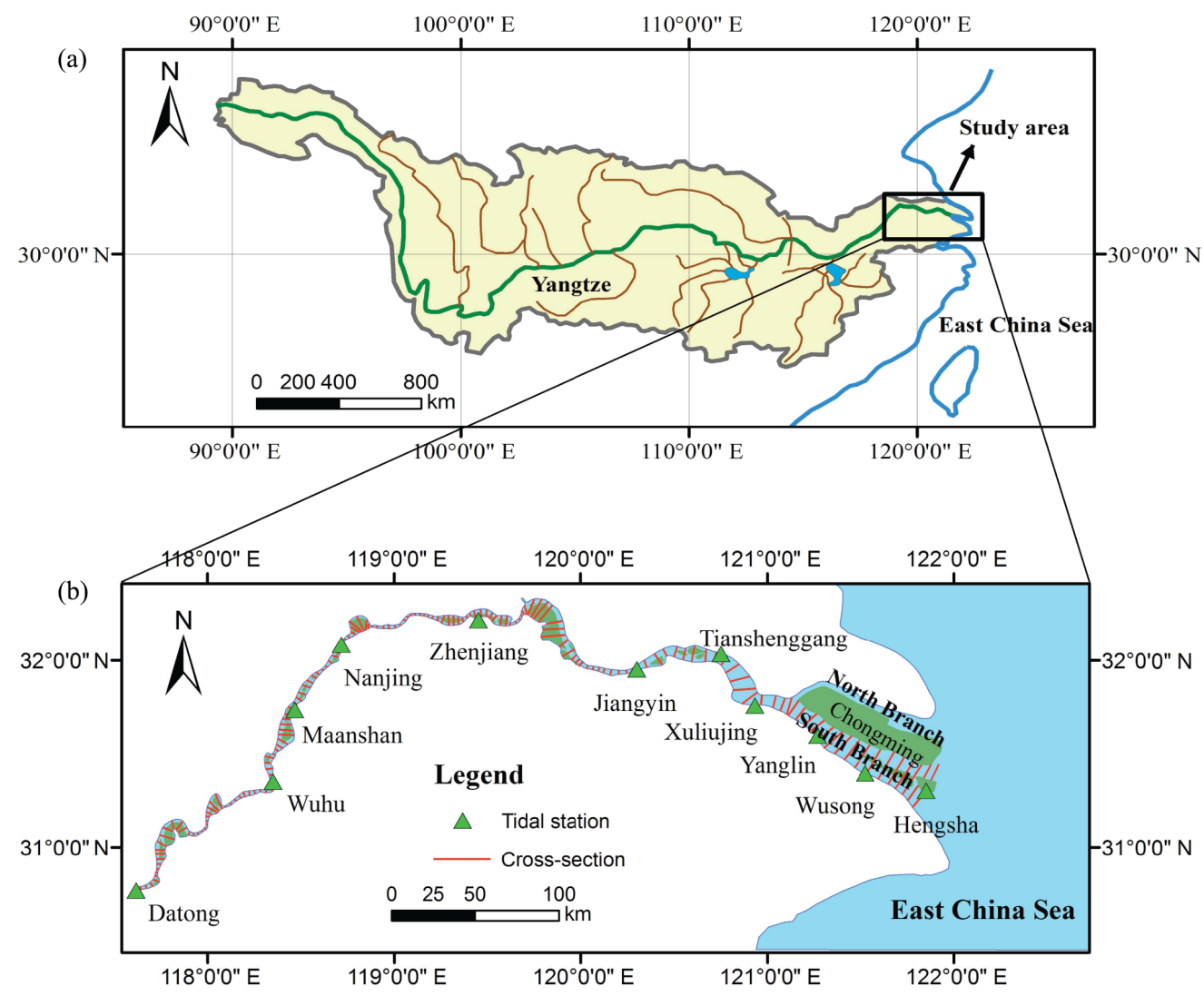

Figure 6. Location of the study area (a) and sketch of the Yangtze estuary showing the positions of the tidal stations and the cross sections extracted along the estuary (b).

imation does not convergence to $V^{2}$ in the river-dominated region $(\varphi>1)$. Thus, we would prefer to use Dronkers' approximation to the friction term, which provides a consistent description for the whole estuary.

\subsection{Solution for the entire estuary}

The dependent parameters $\delta, \mu, \lambda$, and $\varepsilon$ represent the localized tidal dynamics since they depend on local (fixed position) values of the dimensionless tidal amplitude $\zeta$, the shape of the estuary $\gamma$, the bottom friction $\chi$, and the dimensionless river discharge $\varphi$. In order to correctly reproduce the main tidal hydrodynamics along the entire estuary axis, we adopt a multi-reach approach by subdividing the entire estuary into multiple reaches to account for the longitudinal variations of the cross sections (such as water depth and bottom friction). For given amplification number $\delta$ and tidal amplitude $\eta_{0}$ at the seaward boundary of each reach, a tidal amplitude $\eta_{1}$ at a distance $\Delta x($ e.g. $1 \mathrm{~km})$ upstream can be calculated by a simple explicit integration of the amplification number:

$\eta_{1}=\eta_{0}+\frac{\mathrm{d} \eta}{\mathrm{d} x} \Delta x=\eta_{0}+\frac{\eta_{0} \omega \delta}{c_{0}} \Delta x$
Based on the computed $\eta_{1}$ and the geometric feature (e.g. depth) of the next reach, the main tidal dynamics $\delta, \mu, \lambda$, and $\epsilon$ can be obtained by solving the set of Eqs. (6), (14), (15), and (16). Such a process can be repeated by moving the origin of axis for each reach, leading to the solutions for the entire estuary. In principle, the proposed method is valid for an arbitrary bed profile, even with strong longitudinal gradient of bed elevation. An example of MATLAB scripts is provided as supplement.

\section{Application to the Yangtze estuary}

\subsection{Overview of the Yangtze estuary}

The Yangtze River, which is the largest and longest river in the world, originates from the Tibetan Plateau and debouches into the East China Sea (Fig. 6). Characterized by substantial fresh water discharges and meso-scale tides, the Yangtze estuary has a branched structure. Downstream from Xuliujing, the estuary is subdivided into the south branch and north branch divided by Chongming Island (see Fig. 6). The south branch is the main channel conveying both fresh water discharge and sediment into the East China Sea, while the north 


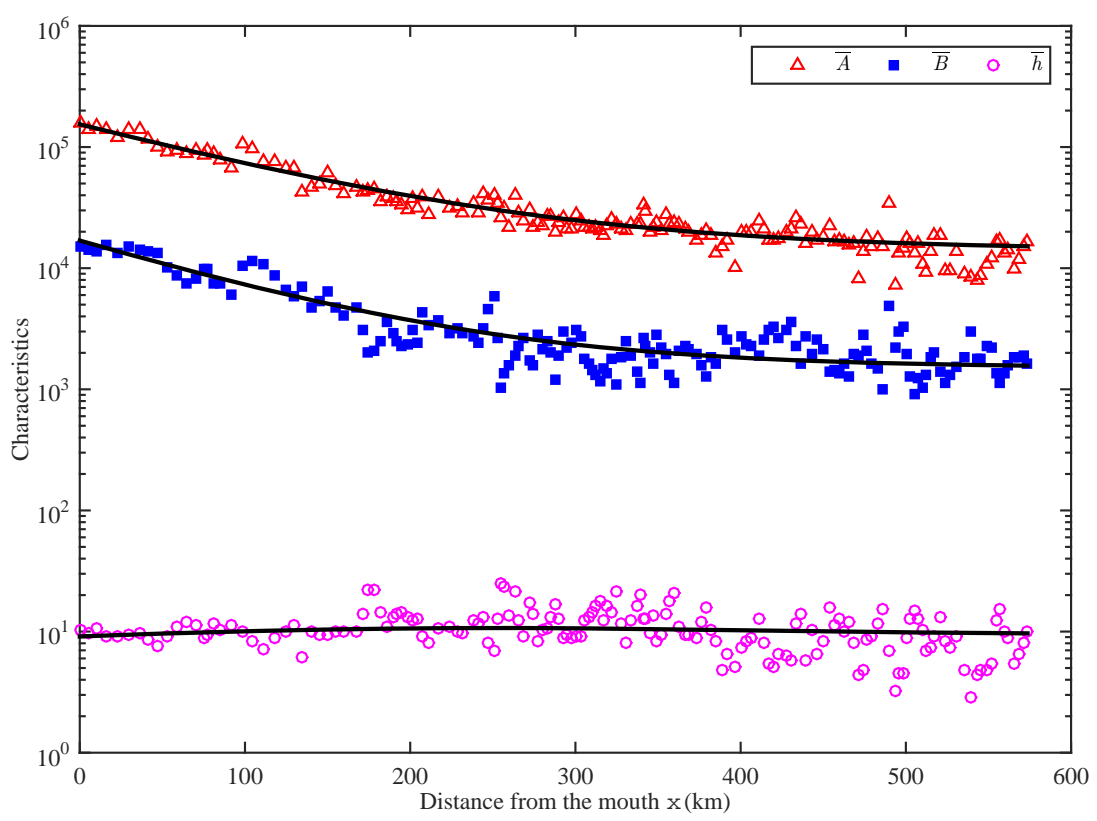

Figure 7. Semi-logarithmic plot of the geometric characteristics (the cross-sectional area $\bar{A}\left(\mathrm{~m}^{2}\right)$, width $\bar{B}(\mathrm{~m})$, and depth $\left.\bar{h}(\mathrm{~m})\right)$ along the Yangtze estuary. The drawn lines represent the best-fitting curves.

branch is barely connected to the main channel and functions in isolation (Zhang et al., 2012). Hence, in this paper we only consider the branched system downstream from the junction between the south branch and the north branch, which in our view functions as an entity for tidal hydrodynamics, so that we may treat it as a whole. Meanwhile, since we concentrate on the dominant tide-river interaction process in the Yangtze estuary, the influence of the net water, salt and sediment fluxes from the north branch into the south branch on the tide-river interaction is neglected.

The total length of the Yangtze estuary is around $600 \mathrm{~km}$ starting from the mouth, located at the Hengsha gauging station, up to the station of Datong, where the influence of tidal flow is vanishing. The estuary has a meso-scale tide with a maximum and mean tidal range of 4.62 and $2.67 \mathrm{~m}$ near the estuary mouth, respectively. The predominant tidal constituent in the Yangtze estuary is semi-diurnal, with averaged ebb and flood duration of 7.4 and $5 \mathrm{~h}$ near the estuary mouth, respectively (Zhang et al., 2012). On the basis of observed data at Datong hydrological station from 1950 to 2012, the annual mean fresh water discharge is $28200 \mathrm{~m}^{3} \mathrm{~s}^{-1}$ and the monthly mean fresh water discharge reaches a maximum of $49500 \mathrm{~m}^{3} \mathrm{~s}^{-1}$ in July and a minimum of $11300 \mathrm{~m}^{3} \mathrm{~s}^{-1}$ in January. It has been suggested that the Canter-Cremers number (representing the ratio of the amount of fresh water to saline water entering the estuary during a tidal period) during a mean spring tide is around 0.1 during the dry season and about 0.24 during the wet season, which suggests a partially mixed salt intrusion in the south branch, where a well-mixed situation occurs during the dry season especially during the spring tide, when the Canter-Cremers number is less than 0.1 (Zhang et al., 2011).

\subsection{Geometry of the Yangtze estuary}

The topography used in this paper was obtained based on the navigation charts in 2007 having corrected to mean sea level of Huanghai 1985 datum. In Fig. 7, the geometric characteristics (i.e. the cross-sectional area, the stream width, the estuary depth) along the Yangtze estuary axis together with the best-fitting curves are shown. We see that both the crosssectional area and stream width can be well represented by using functions of Eqs. (1) and (2), which converge exponentially towards a constant cross section in the river part. The positions of the cross sections are presented in Fig. 6 as red line segments. It is noted that the conventional approach of using ordinary exponential functions (that converge to zero) can only be used if the estuary is subdivided into two reaches, i.e. a more strongly convergent channel in the seaward part and a more prismatic channel in the landward part of the estuary, with an inflection point at the position where the geometry switches from a funnel-shaped estuary to a more prismatic channel (e.g. Cai et al., 2014a). The newly proposed Eqs. (1) and (2), however, describe the shape of the entire estuary as an entity, using only one convergence scale, the convergence lengths $a$ and $b$. From Fig. 7, we observe that the tidally averaged depth gradually increases until the position around $x=245 \mathrm{~km}$ (between Jiangyin and Zhenjiang; see Fig. 6), after which the depth decreases slightly towards a constant value. It should be noted the depth $\bar{h}$ presented in Fig. 7 is the averaged depth relative to mean sea level, while 
(a)
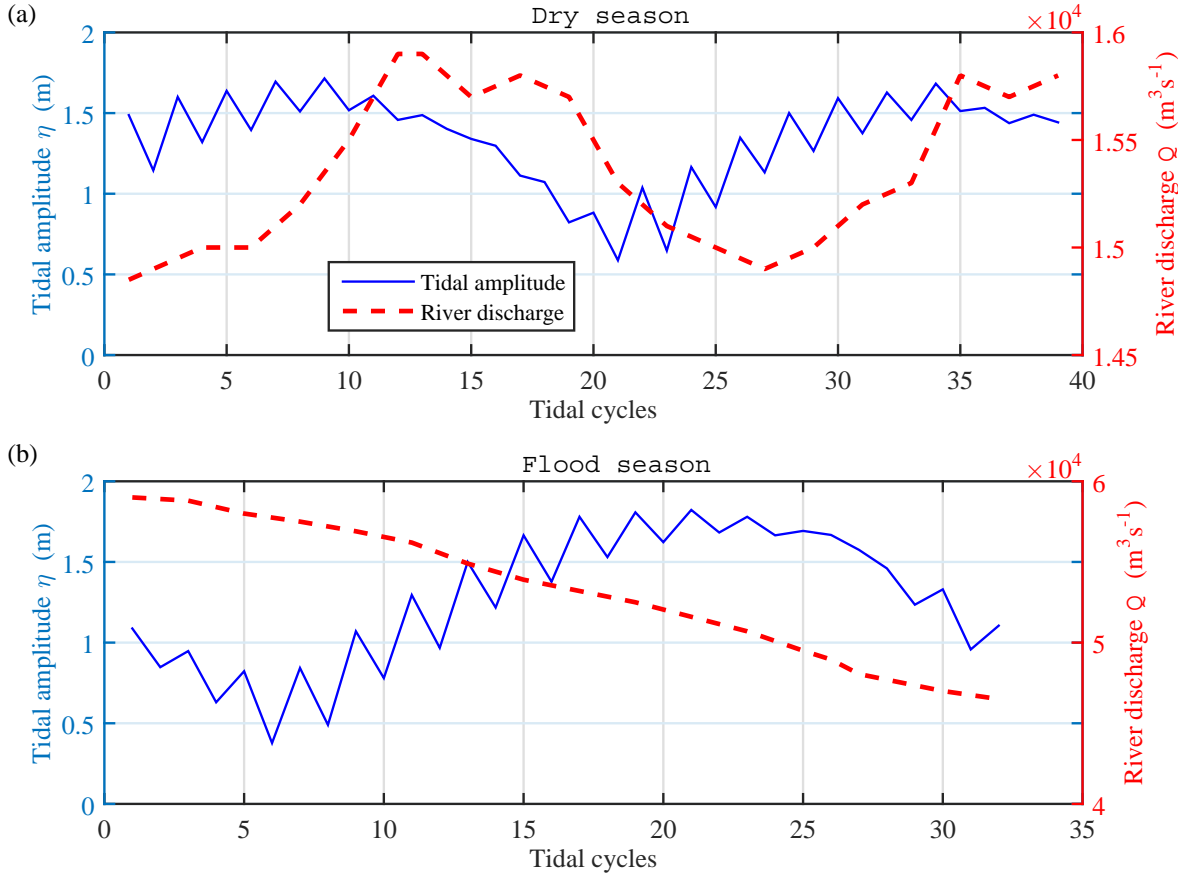

Figure 8. Observations of tidal amplitude at the estuary mouth (Hengsha station) and fresh water discharge at the upstream boundary (Datong station) during the dry (a) and flood (b) season.

the actual depth $\overline{h_{\text {new }}}$ is reproduced by an iterative procedure described in Sect. 2.3.

The calibrated parameters that were obtained by fitting Eqs. (1) and (2) against observed geometry are presented in Table 2, where $R^{2}$ is the coefficient of determination. The enhanced convergence length for cross-sectional area is $117 \mathrm{~km}$, which is slightly larger than that for the width of $103 \mathrm{~km}$.

\subsection{Calibration and verification of hydrodynamics model}

To demonstrate the capability of the hydrodynamic model, the analytical solutions were compared with tidal amplitudes and residual water levels measured along the Yangtze estuary. The data were collected in February 2012 (6-26 February 2012, representing the dry season) and in August 2012 (10-26 August 2012, representing the flood season). In particular, the observed water levels at different gauging stations have been corrected and referenced to mean sea level of Huanghai 1985 datum. We determined the tidal amplitude by averaging the flood tidal amplitude and the ebb tidal amplitude. Figure 8 shows the observed tidal amplitude at the estuary mouth (Hengsha station) and fresh water discharge imposed at the upstream end (Datong station) for both the dry and flood season. Both measurements are tidally averaged values and cover a spring-neap cycle. From Fig. 8, we see a fluctuation of fresh water discharge during the dry season with a range between 14850 and $15900 \mathrm{~m}^{3} \mathrm{~s}^{-1}$, while much larger values are observed during the flood season ranging between 46500 and $59000 \mathrm{~m}^{3} \mathrm{~s}^{-1}$. We observe that the Yangtze estuary has an irregular semi-diurnal tide character, suggesting two tidal cycles within a day. The zigzag line in Fig. 8 has to do with the fact that the tidal amplitude is very different between the two tidal cycles within a day.

The extracted values of tidal amplitudes and residual water levels covering a spring-neap cycle from nine gauging stations along the Yangtze estuary (see their positions in Fig. 6) have been used to calibrate the analytical model. Figure 9 shows the comparison of observed and computed tidal amplitude and residual water level at different gauging stations in the Yangtze estuary for both the dry and flood seasons. We see that the analytical results are in good agreement with observations, suggesting that the analytical model performs well and can correctly reproduce the main tidal dynamics in the Yangtze estuary. The scatter is mainly due to the fact that the simplified geometry adopted in the analytical model does not take account of the irregularities in the channel due to islands and fluctuations in the cross-sectional area. The calibrated friction coefficient $K$ adopted in the seaward reach $(0-245 \mathrm{~km})$ is $75 \mathrm{~m}^{1 / 3} \mathrm{~s}^{-1}$, which is realistic for a silt-mud part of the estuary, while $K=55 \mathrm{~m}^{1 / 3} \mathrm{~s}^{-1}$ in the landward reach $(245-550 \mathrm{~km})$ due to the fact that the sediment becomes coarse (sand) in the riverine part. For simplification, we used a constant storage width ratio $r_{\mathrm{S}}$ of unit, indicating negligible influence of storage area on tidal dynamics. However, we note that the possible effect of bank storage area 

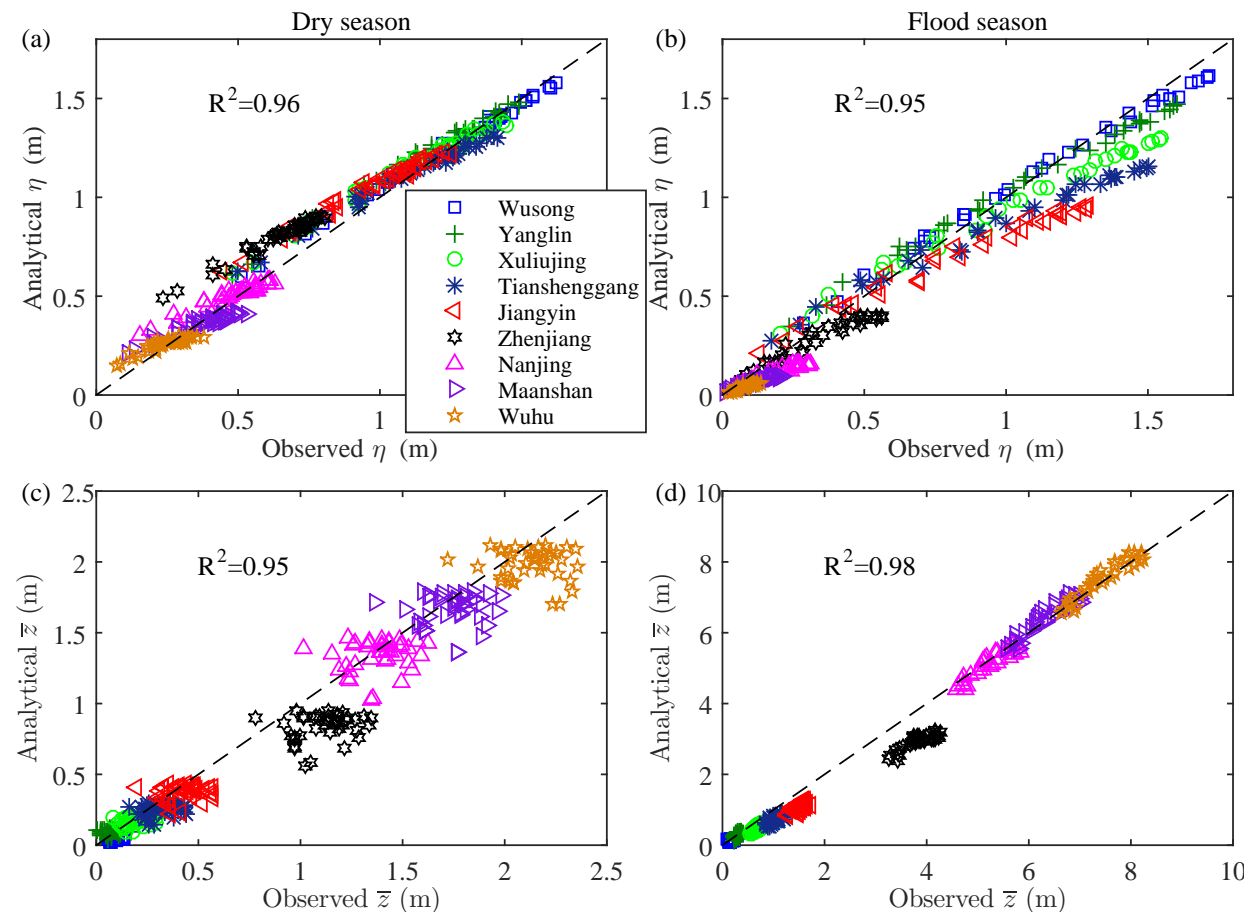

Figure 9. Comparison between analytically computed tidal amplitude $\eta(\mathbf{a}, \mathbf{b})$ and residual water level $\bar{z}$ (c, d) and measurements in the Yangtze estuary during 6-26 February 2012 - (a, c), representing the dry season, and during 10-26 August 2012 - (c, d) representing the flood season.
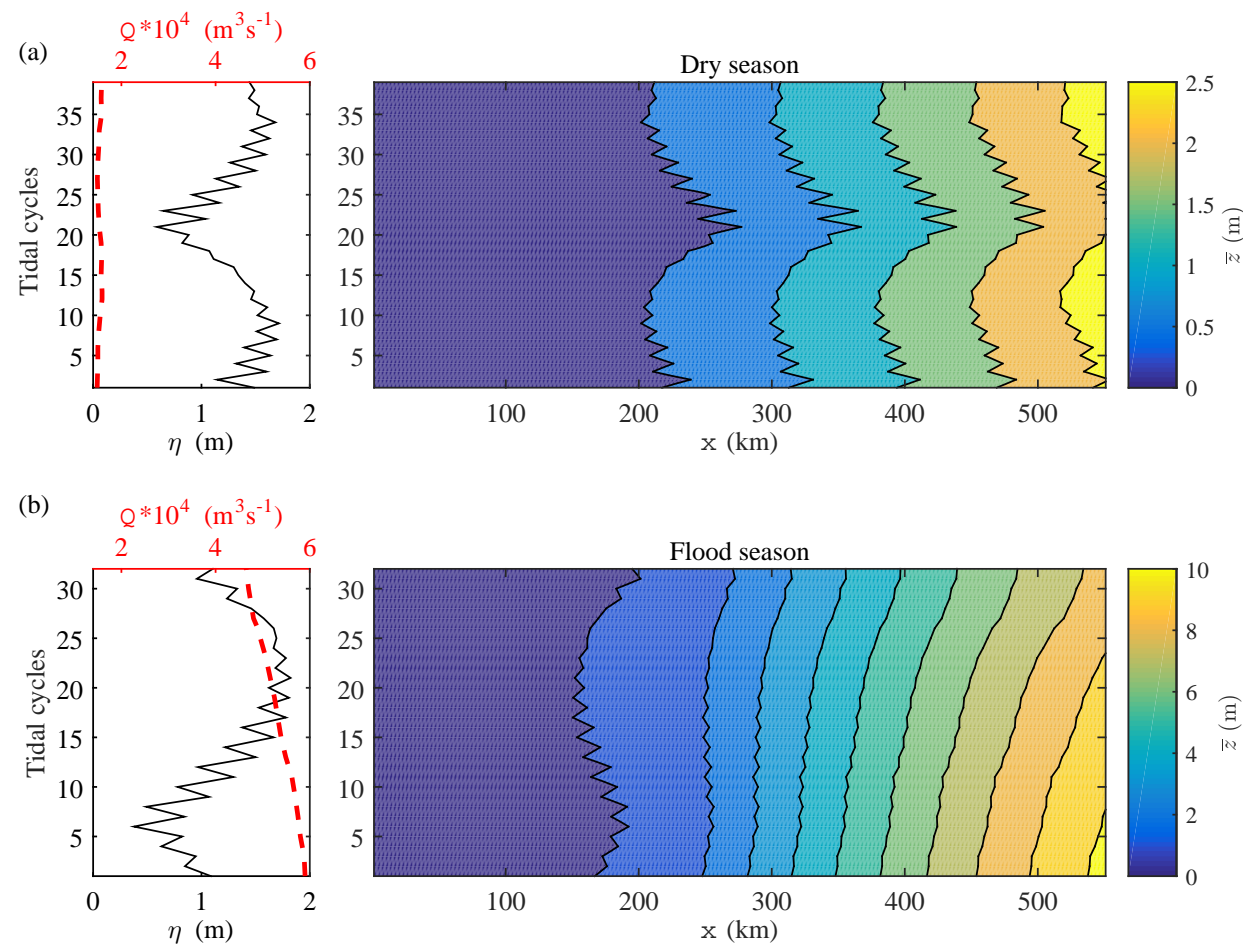

Figure 10. Longitudinal variation of the mean water level along the Yangtze estuary axis as a function of time for the dry season (a) and flood season (b). The left panel shows the corresponding observations of tidal amplitude at Hengsha station and fresh water discharge at Datong station. 
Table 2. The geometric characteristics of the Yangtze estuary.

\begin{tabular}{lrrrr}
\hline Characteristics & $\overline{A_{\mathrm{r}}}\left(\mathrm{m}^{2}\right)$ or $\overline{B_{\mathrm{r}}}(\mathrm{m})$ & $\overline{A_{0}}\left(\mathrm{~m}^{2}\right)$ or $\overline{B_{0}}(\mathrm{~m})$ & $a$ or $b(\mathrm{~km})$ & $R^{2}$ \\
\hline Cross-sectional area $\bar{A}$ & 14113 & 154061 & 117 & 0.98 \\
Width $\bar{B}$ & 1509 & 16897 & 103 & 0.95 \\
\hline
\end{tabular}
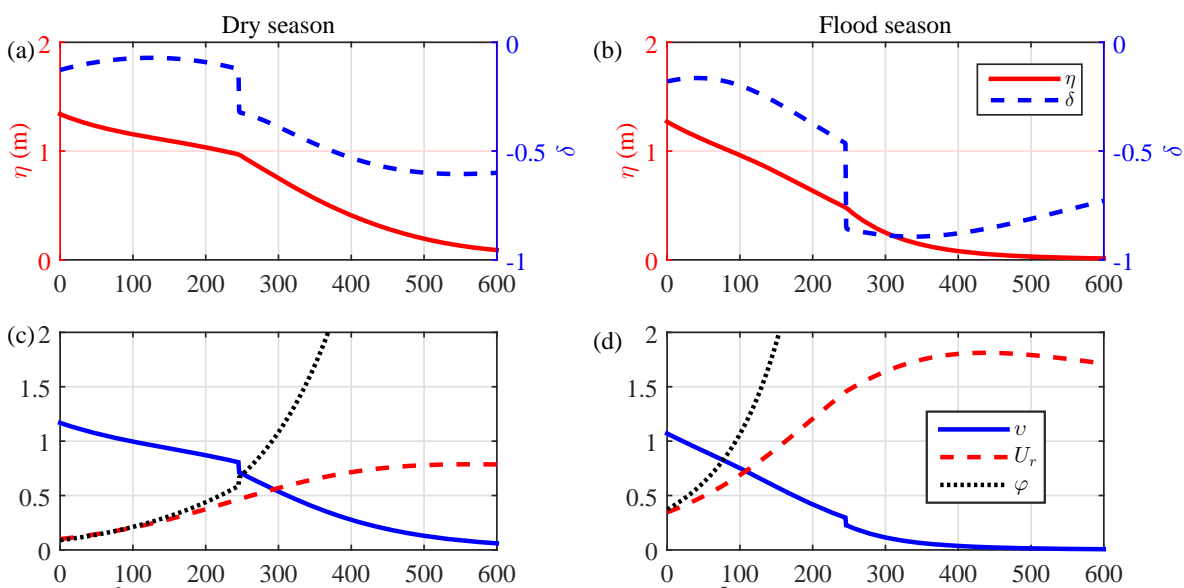

(d)
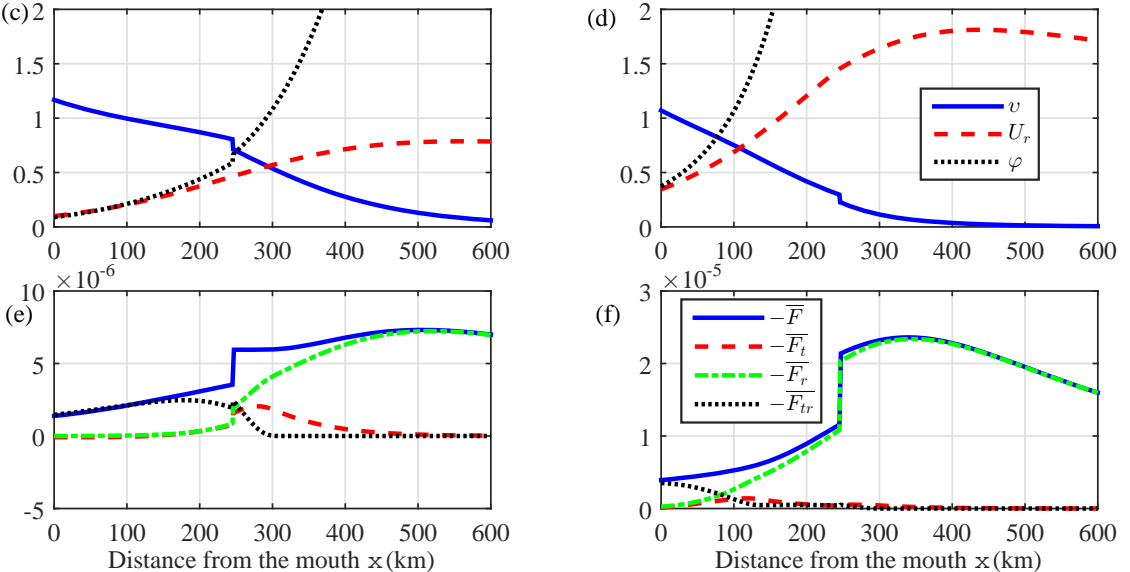

Figure 11. Longitudinal variation of the tidal amplitude and corresponding damping number (a, b), the contributions to the flow velocity by river and tide (c, d), and contributions of river flow and tide to the water level slope (e, f) for the dry $(\mathbf{a}, \mathbf{c}, \mathbf{e})$ and flood season $(\mathbf{b}, \mathbf{d}, \mathbf{f})$ in the Yangtze estuary, in which the results are the averaged values during 6-26 February 2012 (representing the dry season) and during 10-26 August 2012 (representing the flood season), respectively.

could be compensated by the adjustment of the friction coefficient.

\subsection{Influence of tide and river flow on mean water level profile}

Figure 10 shows the longitudinal variation of the mean water level under the influence of tide and river discharge at different tidal cycles for both dry season and flood season. We see that the development of the mean water level is closely related to the fresh water discharge and the tidal forcing at the estuary mouth. During the dry season when the river flow is small compared with the amplitude of tidal flow, we observe that the mean water level is mainly determined by the tidal forcing imposed at the estuary mouth (see Fig. 10a). Conversely, during the flood season when the river flow dominates, especially in the upstream reach of the estuary, we see the mean water level mainly depends on the fresh water discharge, although the tidal amplitude still has a strong influence on the mean water level variation in the seaward part where the tide flow dominates over the river flow (see Fig. 10b).

From the analysis presented in Sect. 2.3, it is suggested that the water level slope $\partial \bar{z} / \partial x$ and the resulted residual water level $\bar{z}$ is controlled by three parameters, i.e. the velocity amplitude, the river flow velocity, and the mean water depth. To illustrate the contributions made by both tidal and riverine forcings, we used the averaged values of $\bar{F}, \overline{F_{\mathrm{t}}}$, $\overline{F_{\mathrm{r}}}$ and $\overline{F_{\text {tr }}}$, which are computed at each tidal cycle during 6-26 February 2012 (representing the dry season) and during 10-26 August 2012 (representing the flood season), respectively. In Fig. 11 we see the longitudinal profiles for the tidal amplitude and its corresponding dimensionless damping rate (Fig. 11a and b), the longitudinal contributions of river and tide to the flow velocity (Fig. 11c and d) and the contributions of river and tide to the tidally averaged water level slope (Fig. 11e and f), for both the dry and the flood season. We observe that the tide-river interaction is the most dominant component in the seaward reach and its influence reduces to null until the critical position where the velocity 

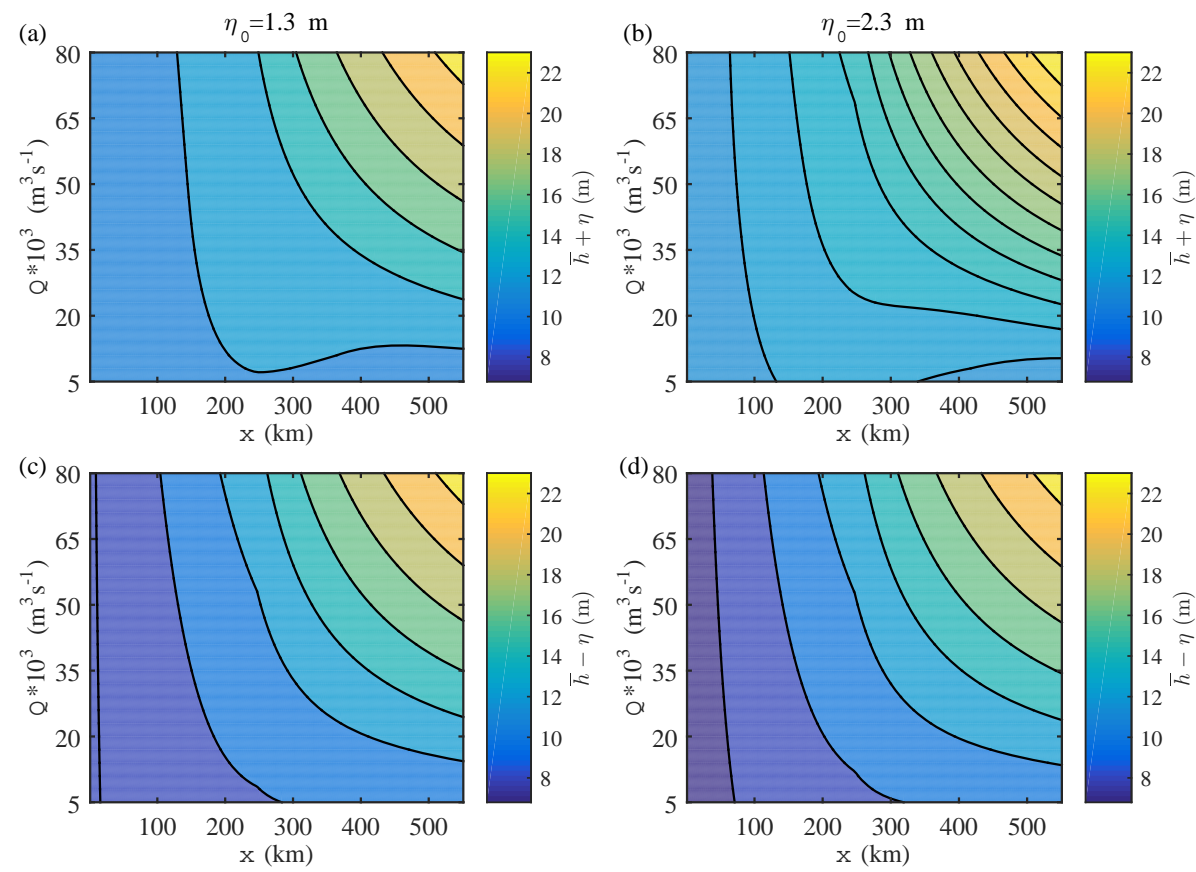

Figure 12. Longitudinal variation of the high water level $\bar{h}+\eta \mathbf{( a , b )}$ and low water level $\bar{h}-\eta(\mathbf{c}, \mathbf{d})$ as a function of fresh water discharge for given tidal amplitude at the estuary mouth $-(\mathbf{a}, \mathbf{b}) \eta_{0}=1.3 \mathrm{~m}$ representing the mean tidal amplitude; $(\mathbf{c}, \mathbf{d}) \eta_{0}=2.3 \mathrm{~m}$ representing the spring tidal amplitude.

amplitude is balanced by the river flow velocity $(\varphi=1)$. We note that both $p_{1}$ and $p_{3}$ in Eq. (20) are equal to 0 when $\varphi>1$; thus, the tide-river component is negligible in the upstream reach of the estuary where the influence of river flow is dominant over the tidal flow. Interestingly, in the transitional zone where $\varphi$ is close to 1 , we see that all three components are crucial for the water level slope since they are proportional to the square of the velocity scale (see Eqs. 1820 ). With regard to the contribution made by tidal forcing, we observe that it increases to a maximum value near the critical position with $\varphi=1$, beyond which it reduces until zero is reached asymptotically. On the other hand, the riverine contribution is monotonously decreasing in the seaward direction. The jump observed around $x=245 \mathrm{~km}$ has to do with the adoption of different friction coefficients in the analytical model. Meanwhile, a slightly negative contribution from tidal forcing is observed near the estuary mouth for the dry season case (see Fig. 11c), which is due to the positive value of the factor $p_{2} / 2+p_{0}$ in Eq. (18).

\subsection{Prediction of high water and low water levels}

Understanding the complex behaviour of mean water level profile and its variation under external forcings (tide, river) is very important for water management to evaluate the influence of river floods, man-made structures (e.g. storm surge barriers, flood gates), and ecosystems protections. In particular, obtaining a first-order estimation of high water $(\bar{h}+\eta)$ and low water $(\bar{h}-\eta)$ levels is useful for flood control and in case problems arise with regard to fresh water withdrawal and navigation when sufficient data are not available to set up a detailed numerical model. In order to explore the response of high water and low water levels to the fresh water discharge, scenario simulation under given mean tidal amplitude $\left(\eta_{0}=1.3 \mathrm{~m}\right)$ and spring tidal amplitude $\left(\eta_{0}=2.3 \mathrm{~m}\right)$ were conducted. The results are shown in Fig. 12. In general, we see that both high water and low water levels increase in landward direction for different fresh water discharge conditions. Only during low flows do we see that the high water level reaches a maximum value; see Fig. 12a and $b$. This is illustrated in Fig. 13.

Figure 13 presents the case of extreme high water occurring near the transitional zone of the Yangtze estuary for a spring tide amplitude $\eta_{0}=2.3 \mathrm{~m}$ and a small fresh water discharge $Q=10000 \mathrm{~m}^{3} \mathrm{~s}^{-1}$. The reason for this phenomenon lies in longitudinal variation of the depth, which has its maximum value near the transition zone. The larger depth causes less friction, which favours amplification. At higher discharges, the friction term gains prominence and the amplification disappears.

It is worth examining the likelihood of an extreme high water level (EHWL) as a function of the probability of exceedance along the estuary, since an EHWL is closely linked to flood control and planning of future engineering works (e.g. dam construction, channel deepening, confinement, or widening of channels). In this paper, we used the 3-parameter generalized extreme-value (GEV) distribution to interpret the 
(a)
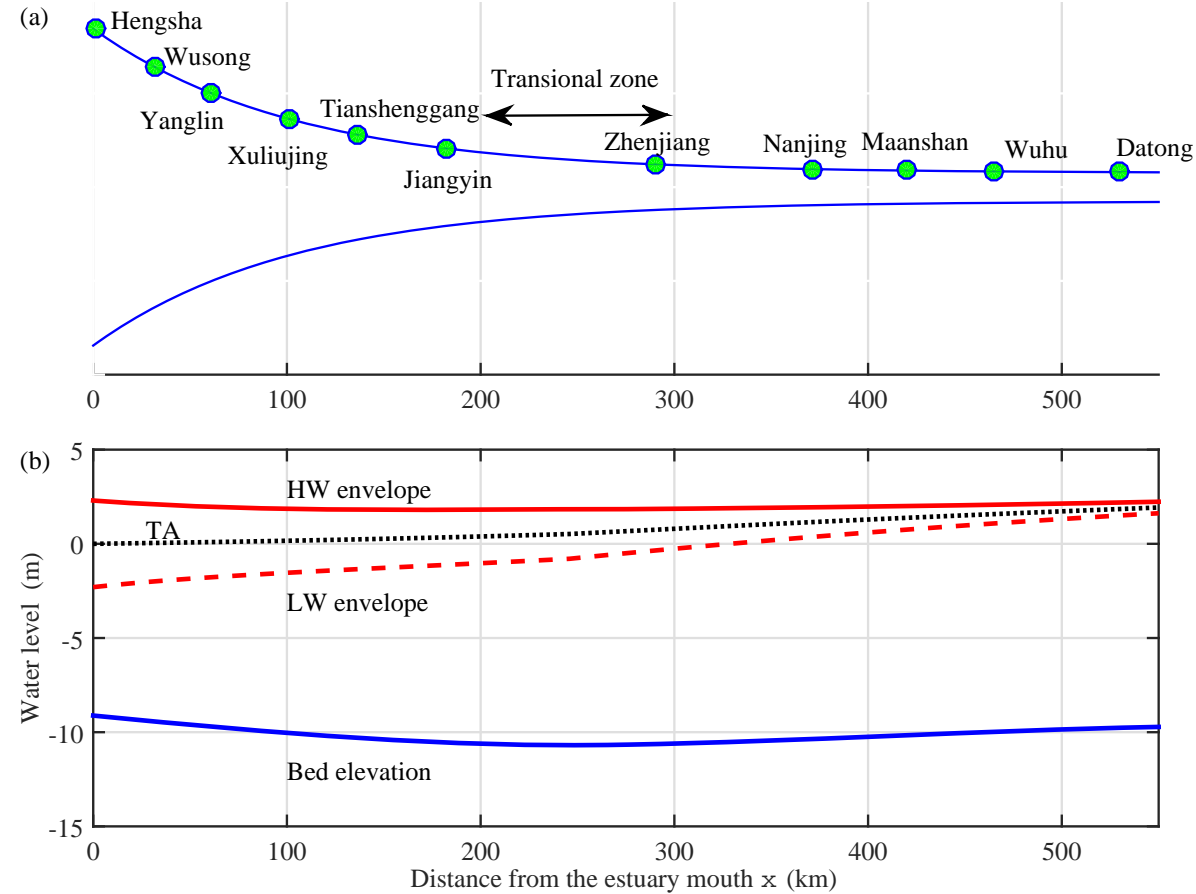

Figure 13. Shape of the Yangtze estuary (a) and the longitudinal computation of the high water (HW) and low water (LW) envelopes along the Yangtze estuary (b) for given values of $\eta_{0}=2.3 \mathrm{~m}, Q=10000 \mathrm{~m}^{3} \mathrm{~s}^{-1}$. The TA curve marks tidal average values.

Table 3. The return values of EHWL (m) at different positions along the Yangtze estuary.

\begin{tabular}{lccccccccc}
\hline $\begin{array}{l}\text { Return period } \\
\text { (years) }\end{array}$ & Wusong & Yanglin & Xuliujing & Tianshenggang & Jiangyin & Zhenjiang & Nanjing & Maanshan & Wuhu \\
\hline 2 & 11.63 & 11.90 & 12.33 & 12.70 & 13.12 & 14.50 & 16.25 & 17.32 & 18.26 \\
5 & 11.64 & 11.93 & 12.38 & 12.75 & 13.22 & 15.03 & 17.16 & 18.40 & 19.46 \\
10 & 11.65 & 11.95 & 12.40 & 12.78 & 13.29 & 15.35 & 17.69 & 19.01 & 20.14 \\
25 & 11.66 & 11.97 & 12.42 & 12.82 & 13.38 & 15.73 & 18.28 & 19.70 & 20.90 \\
50 & 11.66 & 11.97 & 12.43 & 12.84 & 13.44 & 15.99 & 18.68 & 20.16 & 21.40 \\
100 & 11.67 & 11.98 & 12.45 & 12.87 & 13.50 & 16.22 & 19.04 & 20.57 & 21.85 \\
200 & 11.67 & 11.99 & 12.46 & 12.89 & 13.57 & 16.44 & 19.36 & 20.94 & 22.25 \\
500 & 11.67 & 11.99 & 12.47 & 12.92 & 13.64 & 16.70 & 19.75 & 21.37 & 22.73 \\
1000 & 11.68 & 12.00 & 12.48 & 12.95 & 13.70 & 16.88 & 20.01 & 21.67 & 23.05 \\
\hline
\end{tabular}

probability distribution of EHWL. The method has been extensively used in a wide range of regional frequency analysis, such as annual floods, rainfall, wave height, and other natural extremes (Martins and Stedinger, 2000). For given positive random variable $k$, the cumulative distribution function of the GEV distribution is given by

$f\left(k ; \alpha_{1}, \alpha_{2}, \alpha_{3}\right)=\exp \left\{-\left[1+\alpha_{3}\left(\frac{k-\alpha_{1}}{\alpha_{2}}\right)\right]^{-1 / \alpha_{3}}\right\}$,

where $\alpha_{1}, \alpha_{2}$, and $\alpha_{3}$ represent shape, location, and scale of the distribution function, respectively. The critical value $k_{\mathrm{r}}$, which is defined as a value that is expected to be equalled or exceeded on average once every interval of time $T_{\mathrm{r}}$ (with probability of $1 / T_{\mathrm{r}}$ ), can be computed by solving the equa- tion of $f\left(k_{\mathrm{r}} ; \alpha_{1}, \alpha_{2}, \alpha_{3}\right)=1-1 / T_{\mathrm{r}}$ and is given by

$k_{\mathrm{r}}=\frac{\left[-\ln \left(1-1 / T_{\mathrm{r}}\right)\right]^{-\alpha_{3}} \alpha_{2}-\alpha_{2}+\alpha_{1} \alpha_{3}}{\alpha_{3}}$.

In this paper, we first calculated the GEV distribution of maximum mean daily discharge at Datong gauging station based on the available historical record from 1947 to 2012 (see Fig. 14a). The three parameters were estimated by the method of maximum likelihood with $\alpha_{1}=-0.114$, $\alpha_{2}=9400$, and $\alpha_{3}=54300$. From the fitted frequency distribution, we estimated the frequency of the mean daily discharge with a certain return period using Eq. (24). Figure 14b shows the calculated flood discharge at Datong for 2, 5, 10, $20,50,100,200,500$, and 1000 year return period. We as- 

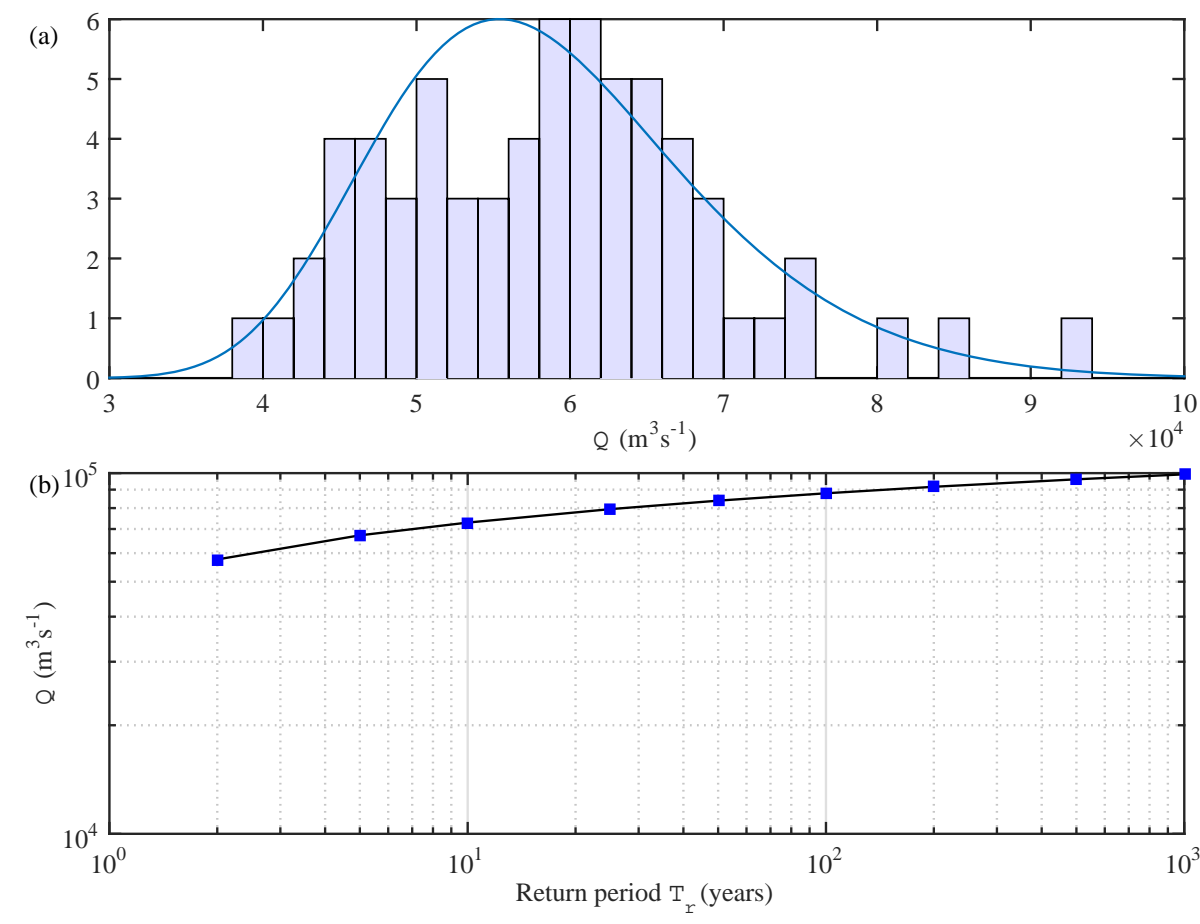

Figure 14. The fitted GEV distribution against observed maximum mean daily discharge (a) and the likelihood of peak discharges as a function of return period (b) at Datong station.

sume a constant tidal amplitude of $\eta_{0}=2.3 \mathrm{~m}$ (corresponding to the mean spring tide) at the seaward boundary. Subsequently, the analytical model can be used to estimate the extreme high water levels along the estuary for floods of different return periods. Table 3 presents the resulting EHWL at different stations along the Yangtze estuary, which can be helpful in designing future engineering works to protect against extreme floods. It can be seen from Table 3 that the EHWL variations in the seaward reach (downstream from Jiangyin) is minor while significant changes occur in the upstream part of the estuary. This is due to the constant spring tidal amplitude imposed at the estuary mouth in the analytical model and thus the variations of EHWL are mainly controlled by the fresh water discharge.

One should be aware that the proposed analytical method only captures the first-order tide-river dynamics in estuaries since the model only accounts for the tidal asymmetry introduced by tide-river interaction while it neglects the tidal asymmetry caused by overtides (e.g. $\mathrm{M}_{4}$ ) and compound tides (e.g. MSf), which may have a significant impact on the residual water level in the central region of the estuary (Guo et al., 2015). For accurate prediction of high water and low water levels, it is required to further study the impact of higher-order terms (e.g. overtides and compound tides) on the generation of the residual water level.

\section{Conclusions}

To investigate the impact of tide-river dynamics on the behaviour of mean water level profile in estuaries, an analytical approach was used to explore the response of residual water level to the two dominant forcings, i.e. tide and river flow. The analytical model allows for quantifying the contributions made by tide and river forcings to the rise of the mean water level along the estuary by making use of the Dronkers' Chebyshev polynomials approximation to the friction term. The distinguishing feature of the present approach is that it allows for analytical prediction of tidally averaged mean water level and tidal amplitude for given inputs of tidal forcing at the estuary mouth, geometry, and fresh water discharge, while the previous studies adopted a linear regression model to estimate the sub-tidal water level and usually required long-term time series of water level or velocity (e.g. Buschman et al., 2009; Sassi and Hoitink, 2013). Shedding new light on the tide-river interaction, the proposed method could be applicable to other estuaries that experience substantial fresh water discharge in a tidal region.

The analytical model requires certain assumptions on the geometry and flow characteristics. The fundamental assumption is that the funnel-prismatic shape of a typical tidal river can be described by Eqs. (1) and (2), where the convergence lengths $(a$ and $b)$ account for the transition from the funnel estuary in the seaward part to the prismatic channel in the upstream part. The other important assumption is that the an- 
alytical solutions of water level and velocity can be described by a residual term (residual water level or river flow velocity) in combination with a simple harmonic wave, which suggests that the model does not account for the interaction between different tidal constituents (e.g. $\mathrm{M}_{2}$ and $\mathrm{M}_{4}$ ). However, since we focus on the reproduction of the first-order hydrodynamics this is not a critical limitation.

Despite the fact that the analytical model requires a certain number of assumptions and thus the results are not as accurate as those of a fully non-linear numerical model, there are some important advantages in using a simplified analytical approach, as compared to numerical models. First of all, the analytical models are completely transparent, allowing direct assessment of the influence of individual variables and parameters on the resulting mean water level. In addition, analytical methods are fast and efficient so that wide ranges of input parameters can be considered. Furthermore, they are more appropriate in data-poor (or ungauged) estuaries since only a minimum amount of (geometrical) data is required. Finally, they provide direct insight into cause-effect relations, which is not as straightforward in numerical models.

The hydrodynamics model has been used to reproduce the main dynamics in the Yangtze estuary, which shows good correspondence with observed data. The model is subsequently used to explore the longitudinal variation of mean water level under a wide range of tidal amplitude and fresh water discharge conditions. It is shown that both tidal amplitude and fresh water discharge tend to rise the mean water level along the Yangtze estuary as a result of the non-linear frictional dissipation. Specifically, the mean water level is influenced primarily by the tide-river interaction in tidedominated region, while it is mainly controlled by the river flow in the upstream part of the estuary. The contribution made by pure tidal influence only becomes important in the transitional zone, where the river flow velocity to tidal velocity amplitude ratio approximately equals 1 . Finally, we also demonstrate that the proposed method can be used to predict the envelopes of high water and low water, which is very useful when assessing the potential influence of intensified extreme river floods and human interventions (e.g. dredging for navigational channel or fresh water withdrawal along the estuary) on along-channel water levels. More importantly, the analytical approach in combination with extreme-value theory can be used to estimate the extreme high water level frequency distribution and the likelihood of various extreme values as a function of return period, which makes the proposed method a useful tool for water management (e.g. flood control measures). 
Appendix A: Derivation of the contributions made by tide and river to the water level slope using Godin's approach

Godin $(1991,1999)$ derived an accurate approximation of the friction term that retained only the first- and third-order terms of the dimensionless velocity:

$F_{\mathrm{G}}=\frac{16}{15 \pi} \frac{U^{\prime 2}}{K^{2} \bar{h}^{4 / 3}}\left[\frac{V}{U^{\prime}}+2\left(\frac{V}{U^{\prime}}\right)^{3}\right]$,

where subscript $\mathrm{G}$ denotes Godin, and $U^{\prime}$ is maximum possible value of the velocity, defined as

$U^{\prime}=v+U_{\mathrm{r}}$.

Substituting the total velocity $V$ from Eq. (3) into the friction term $F_{\mathrm{G}}$ (Eq. A1) and integrating over a tidal period yields components that contribute to the increase of mean water level: the tidal component

$\overline{F_{t-\mathrm{G}}}=-\frac{16}{15 \pi} \frac{1}{K^{2} \bar{h}^{4 / 3}} \frac{\varphi}{1+\varphi} 4 v^{2}$,

the riverine component

$\overline{F_{\mathrm{r}-\mathrm{G}}}=-\frac{16}{15 \pi} \frac{1}{K^{2} \bar{h}^{4 / 3}} \frac{\varphi}{1+\varphi} 3 U_{\mathrm{r}}^{2}$,

and the tide-river interaction

$\overline{F_{\text {tr }-\mathrm{G}}}=-\frac{16}{15 \pi} \frac{1}{K^{2} \bar{h}^{4 / 3}} \frac{\varphi}{1+\varphi} 2 v U_{\mathrm{r}}$.

It should be noted that the main dynamics (e.g. the velocity amplitude $v$, the estuary depth $\bar{h}$ ) should be recalculated if we adopted Godin's approximation to the friction term A1, since the friction factor $\Gamma$ in the damping Eq. (6) becomes (for details see the supplemental material in Cai et al., 2014b)

$\Gamma=G_{0}+G_{1}(\mu \lambda)^{2}+\zeta\left[G_{2} \mu \lambda+G_{3} /(\mu \lambda)\right]$,

with

$G_{0}=\frac{16}{15 \pi} \frac{1+2 \varphi+7 \varphi^{2}}{1+\varphi}$,

$G_{1}=\frac{32}{15 \pi} \frac{1}{1+\varphi}$,

$G_{2}=\frac{128}{15 \pi} \frac{\varphi}{1+\varphi}$,

$G_{3}=\frac{64}{15 \pi} \frac{\varphi / 3+2 \varphi^{2} / 3+\varphi^{3}}{1+\varphi}$.

Making use of the friction factor $\Gamma$ (Eq. A6), the analytical solutions for the main dependent parameters (i.e. the damping number $\delta$, the velocity number $\mu$, the celerity number $\lambda$ and the phase lag $\varepsilon$ ) can be obtained by solving the set of four implicit Eqs. (6), (14), (15), and (16).

Based on the obtained hydrodynamics along the estuary, it follows directly from Eq. (17) that the contributions made by tidal flow alone, river flow alone, and tide-river interaction on the residual water level slope can be computed through Eqs. (A3)-(A5).

Buschman et al. (2009) also decomposed the tidally averaged friction term and derived the contributions by different components (see their Eq. 9). For a simple case with only one predominant tidal constituent (e.g. $\mathrm{M}_{2}$ ), their results can be rewritten as our notations:

$\overline{F_{r-B}}=-\frac{16}{15 \pi} \frac{U^{\prime 2}}{K^{2} \bar{h}^{4 / 3}}\left[\frac{U_{r}}{U^{\prime}}+2\left(\frac{U_{r}}{U^{\prime}}\right)^{3}\right]$,

$\overline{F_{t r-B}}=-\frac{16}{15 \pi} \frac{U^{\prime 2}}{K^{2} \bar{h}^{4 / 3}}\left[3 \frac{U_{r}}{U^{\prime}}\left(\frac{v}{U^{\prime}}\right)^{2}\right]$,

where the subscript B denotes Buschman. Note that here the component due to tidal asymmetry does not exist because we only consider one predominant tidal constituent. It is important to note that Buschman et al. (2009) used the expressions contained in square brackets on the right-hand side of Eqs. (A8) and (A9) to quantify the contributions by river flow alone and tide-river interaction to the generation of the tidally averaged friction, rather than the residual water level slope. In fact, substituting the expression of the maximum velocity $U^{\prime}=v+U_{r}$ into Eqs. (A8) and (A9), we would end up with Eqs. (A1)-(A3) quantifying the contributions made by tidal component, river component, and tide-river interaction to the residual water level slope.

Figure A1 shows the results obtained by using Dronkers' Chebyshev polynomial approximation (thick lines) and Godin's approximation to the friction term (thin lines). We can see both methods can well reproduce the tidal dynamics (e.g. tidal amplitude and velocity amplitude $v$ in Fig. A1a, $\mathrm{b}, \mathrm{c}, \mathrm{d})$ along the estuary. However, Godin's approximation to $V|V|$ does not convergence to $V^{2}$ in the upstream part of the estuary, where the river flow is dominant over tidal flow. In river-dominated region, the tidally averaged friction term is given by $\bar{F}=\overline{\frac{V^{2}}{K^{2} \bar{h}^{4 / 3}}}=\frac{v^{2} / 2+U_{r}^{2}}{K^{2} \bar{h}^{4 / 3}}$, with contributions made by tide and river flow being $\overline{F_{\mathrm{t}}}=\frac{v^{2}}{K^{2} \bar{h}^{4 / 3}}$ and $\overline{F_{\mathrm{r}}}=\frac{U_{r}^{2}}{K^{2} \bar{h}^{4 / 3}}$, respectively. The contribution made by tide-river interaction is null in the river-dominated region. In Fig. A1c, d, we observe a significant contribution of tide-river interaction in the upstream part $(\varphi>1)$ on the residual water level slope using Godin's approximation, which is artificial due to the fitting of the quadratic velocity $V|V|$. Consequently, we would prefer to adopt Dronkers' approximation to the friction term, which provides a consistent description for the whole estuary. 

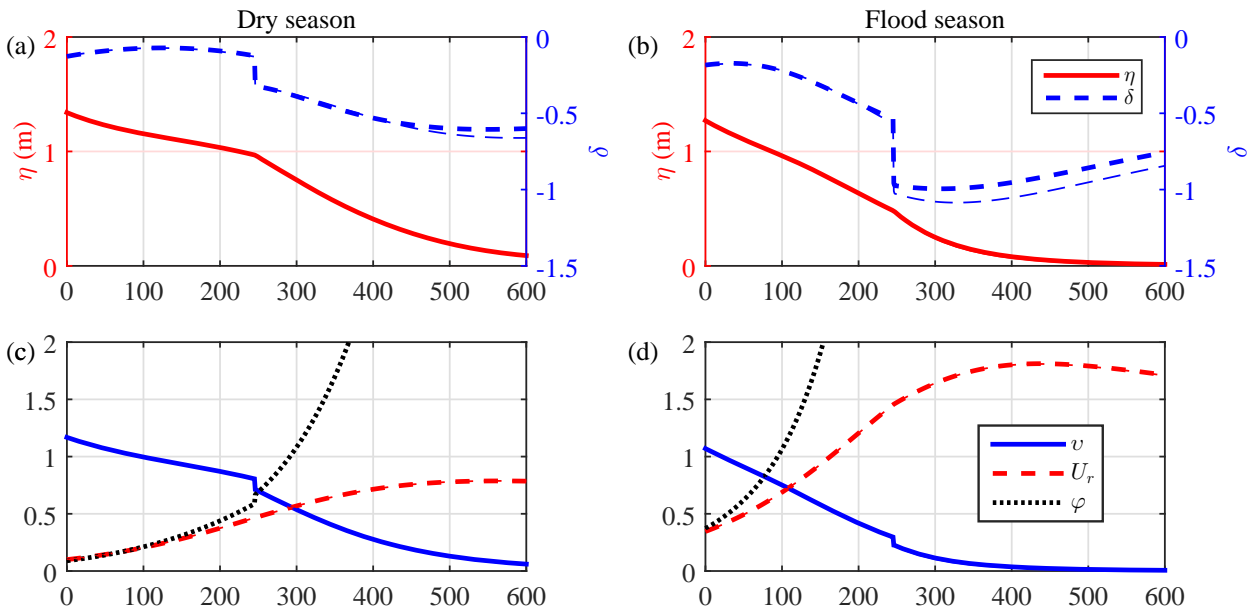

(d)
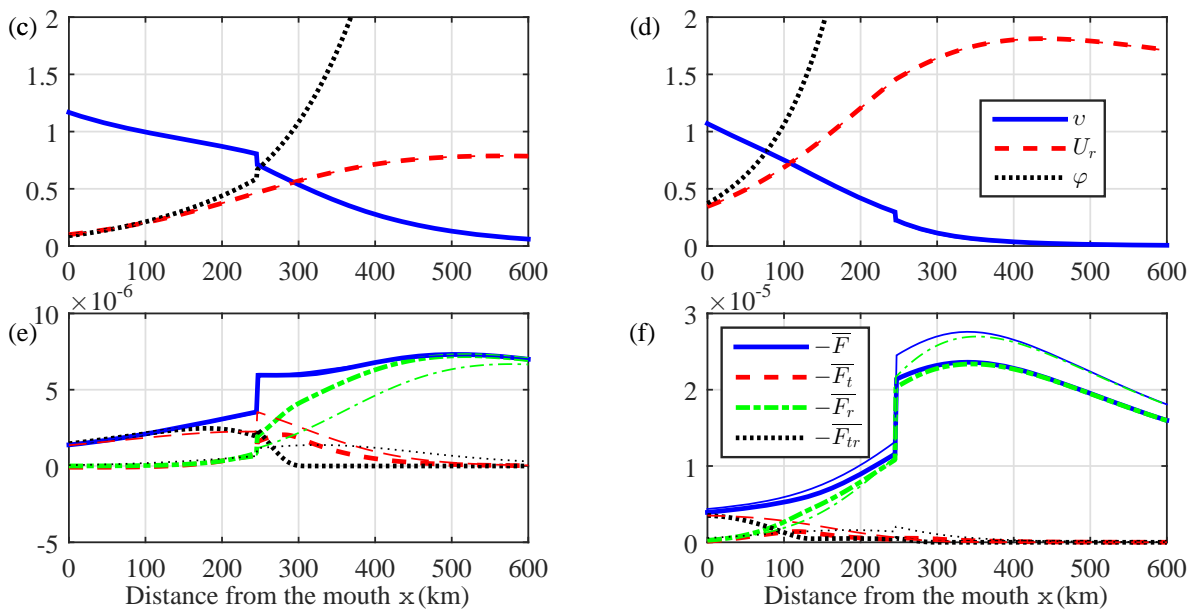

Figure A1. Longitudinal variation of the tidal amplitude and corresponding damping number (a, b), the contributions to the flow velocity by river and tide (c, d), and contributions of river flow and tide to the water level slope (e, f) for the dry (a, $\mathbf{c}, \mathbf{e})$ and flood season $(\mathbf{b}, \mathbf{d}, \mathbf{f})$ in the Yangtze estuary, in which the results are the averaged values during 6-26 February 2012 (representing the dry season) and during 10-26 August 2012 (representing the flood season), respectively. The thin lines represent the results using Godin's approximation to the friction term, while the thick lines represent the results using Dronkers' Chebyshev polynomials approximation to the friction term. 
Table A1. Nomenclature.

\begin{tabular}{|c|c|}
\hline$a$ & Convergence length of cross-sectional area \\
\hline $\bar{A}$ & Tidally averaged cross-sectional area of flow \\
\hline$\overline{A_{0}}$ & $\begin{array}{l}\text { Tidally averaged cross-sectional area at the } \\
\text { estuary mouth }\end{array}$ \\
\hline$\overline{A_{\mathbf{r}}}$ & Asymptotic riverine cross-sectional area \\
\hline$b$ & Convergence length of width \\
\hline $\bar{B}$ & Tidally averaged stream width \\
\hline$\overline{B_{0}}$ & Tidally averaged width at the estuary mouth \\
\hline$\overline{B_{\mathbf{r}}}$ & Asymptotic riverine stream width \\
\hline$c$ & Wave celerity \\
\hline$c_{0}$ & $\begin{array}{l}\text { Celerity of a frictionless wave in a prismatic } \\
\text { channel }\end{array}$ \\
\hline$f$ & $\begin{array}{l}\text { Cumulative distribution function of the } \\
\text { GEV distribution }\end{array}$ \\
\hline$F$ & $\begin{array}{l}\text { Dronkers' friction term accounting for } \\
\text { river discharge }\end{array}$ \\
\hline$F_{\mathrm{G}}$ & $\begin{array}{l}\text { Godin's friction term accounting for } \\
\text { river discharge }\end{array}$ \\
\hline$F_{\mathrm{t}}$ & $\begin{array}{l}\text { Contribution made by tide to the tidally } \\
\text { averaged friction }\end{array}$ \\
\hline$F_{\mathrm{r}}$ & $\begin{array}{l}\text { Contribution made by river discharge to } \\
\text { the tidally averaged friction }\end{array}$ \\
\hline$F_{\mathrm{tr}}$ & $\begin{array}{l}\text { Contribution made by tide-river interaction to } \\
\text { the tidally averaged friction }\end{array}$ \\
\hline$F_{\mathrm{t}-\mathrm{G}}$ & $\begin{array}{l}\text { Contribution made by tide to the tidally } \\
\text { averaged friction in Godin's approach }\end{array}$ \\
\hline$F_{\mathrm{r}-\mathrm{G}}$ & $\begin{array}{l}\text { Contribution made by river discharge to } \\
\text { the tidally averaged friction in Godin's approach }\end{array}$ \\
\hline$F_{\mathrm{tr}-\mathrm{G}}$ & $\begin{array}{l}\text { Contribution made by tide-river interaction to } \\
\text { the tidally averaged friction in Godin's approach }\end{array}$ \\
\hline$\underline{g}$ & Acceleration due to gravity \\
\hline $\bar{h}$ & Tidal average depth relative to mean sea level \\
\hline$\overline{h_{\text {new }}}$ & Actual depth relative to mean water level \\
\hline$k$ & Positive random variable \\
\hline$K$ & Manning-Strickler friction factor \\
\hline$p_{0}, p_{1}, p_{2}, p_{3}$ & $\begin{array}{l}\text { Chebyschev coefficients accounting for } \\
\text { river discharge }\end{array}$ \\
\hline$Q$ & Fresh water discharge \\
\hline$r_{\mathrm{S}}$ & Storage width ratio \\
\hline$t$ & Time \\
\hline$U_{\mathrm{t}}$ & Tidal velocity \\
\hline$U_{\mathrm{r}}$ & River velocity \\
\hline$U^{\prime}$ & The maximum possible velocity in Godin's approach \\
\hline$V$ & Lagrangean Velocity for a moving water particle \\
\hline$V_{\mathrm{HW}}$ & Velocity at HW \\
\hline$V_{\mathrm{LW}}$ & Velocity at LW \\
\hline$x$ & Distance from the estuary mouth \\
\hline $\bar{z}$ & Mean water level or residual water level \\
\hline$\alpha, \beta$ & Functions of dimensionless river discharge term $\varphi$ \\
\hline$\gamma$ & Estuary shape number \\
\hline$\Gamma$ & Dimensionless damping parameter \\
\hline$\delta$ & Damping number \\
\hline$\varepsilon$ & Phase lag between HW and HWS (or LW and LWS) \\
\hline$\zeta$ & Tidal amplitude to depth ratio \\
\hline$\eta$ & Tidal amplitude \\
\hline$\eta_{0}$ & Tidal amplitude at the seaward boundary \\
\hline
\end{tabular}




\section{The Supplement related to this article is available online at doi:10.5194/hess-20-1177-2016-supplement.}

Acknowledgements. The authors would like to thank Maximiliano Sassi and the other anonymous referee for their constructive comments and suggestions, which have substantially improved this paper. This research was financially supported by National Natural Science Foundation of China with the reference no. 41476073.

Edited by: E. Zehe

\section{References}

Buschman, F. A., Hoitink, A. J. F., van der Vegt, M., and Hoekstra, P.: Subtidal water level variation controlled by river flow and tides, Water Resour. Res., 45, W10420, doi:10.1029/2009WR008167, 2009.

Cai, H., Savenije, H. H. G., and Jiang, C.: Analytical approach for predicting fresh water discharge in an estuary based on tidal water level observations, Hydrol. Earth Syst. Sci., 18, 4153-4168, doi:10.5194/hess-18-4153-2014, 2014a.

Cai, H., Savenije, H. H. G., and Toffolon, M.: Linking the river to the estuary: influence of river discharge on tidal damping, Hydrol. Earth Syst. Sci., 18, 287-304, doi:10.5194/hess-18-2872014, 2014b.

Dottori, F., Martina, M. L. V., and Todini, E.: A dynamic rating curve approach to indirect discharge measurement, Hydrol. Earth Syst. Sci., 13, 847-863, doi:10.5194/hess-13-847-2009, 2009.

Dronkers, J. J.: Tidal computations in River and Coastal Waters, Elsevier, New York, PP1-518, 1964.

Gay, P. and O'Donnell, J.: Comparison of the Salinity Structure of the Chesapeake Bay, the Delaware Bay and Long Island Sound Using a Linearly Tapered Advection-Dispersion Model, Estuar. Coast., 32, 68-87, doi:10.1007/s12237-008-9101-4, 2009.

Gay, P. S. and O'Donnell, J.: A simple advection-dispersion model for the salt distribution in linearly tapered estuaries, J. Geophys. Res., 112, 120, 3499-3521, doi:10.1029/2006jc003840, 2007.

Godin, G.: Compact Approximations to the Bottom Friction Term, for the Study of Tides Propagating in Channels, Cont. Shelf. Res., 11, 579-589, doi:10.1016/0278-4343(91)90013-V, 1991.

Godin, G.: The propagation of tides up rivers with special considerations on the upper Saint Lawrence river, Estuar. Coast Shelf S., 48, 307-324, doi:10.1006/ecss.1998.0422, 1999.

Godin, G. and Martinez, A.: Numerical Experiments to Investigate the Effects of Quadratic Friction on the Propagation of Tides in a Channel, Cont. Shelf. Res., 14, 723-748, doi:10.1016/02784343(94)90070-1, 1994.

Guo, L., van der Wegen, M., Jay, D. A., Matte, P., Wang, Z. B., Roelvink, D. J., and He, Q.: River-tide dynamics: Exploration of non-stationary and nonlinear tidal behavior in the Yangtze River estuary, J. Geophys. Res., doi:10.1002/2014JC010491, 2015.

Ippen, A. T.: Tidal dynamics in estuaries, part I: Estuaries of rectangular section, in: Estuary and Coastline Hydrodynamics, edited by: Ippen, A. T., 494-522, McGraw-Hill, New York, 1966.
Jay, D. A. and Flinchem, E. P.: Interaction of fluctuating river flow with a barotropic tide: A demonstration of wavelet tidal analysis methods, J. Geophys. Res., 102, 5705-5720, doi:10.1029/96JC00496, 1997.

Jay, D. A., Leffler, K., Diefenderfer, H. L., and Borde, A. B.: TidalFluvial and Estuarine Processes in the Lower Columbia River: I. Along-Channel Water Level Variations, Pacific Ocean to Bonneville Dam, Estuar. Coast, 38, 415-433, doi:10.1007/s12237014-9819-0, 2015.

Jones, B. E.: A method of correcting river discharge for a changing stage, vol. Water Supply 375, US Geological Survey, 1916.

Kukulka, T. and Jay, D. A.: Impacts of Columbia River discharge on salmonid habitat: 1. A nonstationary fluvial tide model, J. Geophys. Res., 108, 3293, doi:10.1029/2002JC001382, 2003a.

Kukulka, T. and Jay, D. A.: Impacts of Columbia River discharge on salmonid habitat: 2 . Changes in shallow-water habitat, J. Geophys. Res., 108, 3294, doi:10.1029/2003JC001829, 2003b.

LeBlond, P. H.: Forced fortnightly tides in shallow waters, Atmos. Ocean, 17, 253-264, doi:10.1080/07055900.1979.9649064, 1979.

Martins, E. S. and Stedinger, J. R.: Generalized maximumlikelihood generalized extreme-value quantile estimators for hydrologic data, Water Resour. Res., 36, 737-744, doi:10.1029/1999wr900330, 2000.

Prandle, D. and Rahman, M.: Tidal Response in Estuaries, J. Phys. Oceanogr., 10, 1552-1573, doi:10.1175/15200485(1980)010<1552:Trie/textgreater2.0.CO;2, 1980.

Sassi, M. G. and Hoitink, A. J. F.: River flow controls on tides and tide-mean water level profiles in a tidal freshwater river, J. Geophys. Res., 118, 4139-4151, doi:10.1002/Jgrc.20297, 2013.

Savenije, H. H. G.: Analytical expression for tidal damping in alluvial estuaries, J. Hydraul. Eng., 124, 615-618, doi:10.1061/(ASCE)0733-9429(1998)124:6(615), 1998.

Savenije, H. H. G.: A simple analytical expression to describe tidal damping or amplification, J. Hydrol., 243, 205-215, doi:10.1016/S0022-1694(00)00414-5, 2001.

Savenije, H. H. G.: Salinity and Tides in Alluvial Estuaries, Elsevier, New York, PP1-194, 2005.

Savenije, H. H. G.: Salinity and Tides in Alluvial Estuaries, completely revised 2nd edition, http://www.salinityandtides.com (Last access: 10 June 2015), 2012.

Savenije, H. H. G., Toffolon, M., Haas, J., and Veling, E. J. M.: Analytical description of tidal dynamics in convergent estuaries, $\mathrm{J}$ Geophys. Res., 113, C10025, doi:10.1029/2007JC004408, 2008.

Toffolon, M., Vignoli, G., and Tubino, M.: Relevant parameters and finite amplitude effects in estuarine hydrodynamics, J. Geophys. Res., 111, C10014, doi:10.1029/2005JC003104, 2006.

Vignoli, G., Toffolon, M., and Tubino, M.: Non-linear frictional residual effects on tide propagation, in: Proceedings of XXX IAHR Congress, vol. A, 24-29 August 2003, 291-298, Thessaloniki, Greece, 2003.

Zhang, E. F., Savenije, H. H. G., Wu, H., Kong, Y. Z., and Zhu, J. R.: Analytical solution for salt intrusion in the Yangtze Estuary, China, Estuar. Coast Shelf S., 91, 492-501, doi:10.1016/j.ecss.2010.11.008, 2011.

Zhang, E. F., Savenije, H. H. G., Chen, S. L., and Mao, X. H.: An analytical solution for tidal propagation in the Yangtze Estuary, China, Hydrol. Earth Syst. Sci., 16, 3327-3339, doi:10.5194/hess-16-3327-2012, 2012. 